\title{
Intergenerational Educational Effects of Mass Imprisonment in America
}

\author{
John Hagan' and Holly Foster ${ }^{2}$
}

\begin{abstract}
In some American schools, about a fifth of the fathers have spent time in prison during their child's primary education. We examine how variation across schools in the aggregation and concentration of the mass imprisonment of fathers is associated with their own children's intergenerational educational outcomes and "spills over" into the attainments of other students. We assess the association of this interinstitutional and intergenerational "prison through school pathway" with downward and blocked educational achievement. Educational and economic resources and other predisposing variables partially explain school-linked effects of paternal imprisonment on measures of children's educational outcomes. However, we find that the net negative school-level association of paternal imprisonment with educational outcomes persists even after we introduce school- and individual-level measures of a wide range of mediating processes and extraneous control variables. We discuss paternal imprisonment as a form of "marked absence." The significance of elevated levels of paternal imprisonment in schools is perhaps most apparent in its negative association with college completion, the educational divide that now most dramatically disadvantages individuals and groups in American society.
\end{abstract}

\section{Keywords}

achievement, adolescents, incarceration, schools, students

\section{THE EFFECTS OF MASS IMPRISONMENT}

David Garland (2001b:1) coined the term mass imprisonment to describe the twenty-first-century penal confinement of more than 2 million Americans, which he calls "an unprecedented event in the history of the USA and, more generally, in the history of liberal democracy." The United States constitutes about one twentieth of the world's population, but our jails and prisons hold about one quarter of the world's inmates (Blumstein 2007). Garland's mass imprisonment concept highlights both the overall aggregate size and the selectively concentrated form of this confinement. "Imprisonment becomes mass imprisonment," Garland (2001b:1) observes, "when it ceases to be the incarceration of individual offenders and becomes the systematic imprisonment of whole groups of the population" (see also Garland 2001a; Simon 2007; Wildeman 2009).

The groups incarcerated are increasingly described in education-related terms. Thus, Pettit and Western (2004; Western 2006) report that nearly two thirds of black male high school

\footnotetext{
'Northwestern University, Chicago, IL, USA

${ }^{2}$ Texas A\&M University, College Station, USA

Corresponding Author:

John Hagan, Northwestern University, 1810 Chicago

Avenue Chicago, IL 60208

Email: j-hagan@northwestern.edu
} 
dropouts in their 30s have spent time in jail or prison and that black males of this age are more likely to have been incarcerated than to have gone to college. In an earlier era, military service was a potential turning point experience available even to youth caught up in the criminal justice system and the GI Bill provided educational opportunities for veterans (Sampson and Laub 1995). However, for minority men incarceration is today much more likely than military service to mark the transition to adulthood and derail their educational prospects.

Clear (2007:68) extends this perspective by noting that mass incarceration is so spatially concentrated in neighborhoods and schools that "we can think of these sites as "prison places." Neighborhoods and schools can themselves take on characteristics of prisons (Sander 2010). Police in inner-city schools often patrol entrances, hallways, and exits much like prison guards (Tuzzolo and Hewitt 2006-2007). Schools can play a preparatory role for incarceration (e.g., Fenning and Rose 2007), and as a result there is a burgeoning research literature on the "school to prison pipeline" (Sander 2010). This literature identifies the ways in which a punitive orientation to crime in America has brought the police directly into schools to enforce zero tolerance disciplinary policies (Solomon 2004) and integrate information and control systems placing youth at increased risk of justice system contact and ultimately incarceration (Christle, Jolivette, and Nelson 2005; Hirschfield 2008; Kupchicka and Monahan 2006).

Research in the sociology of education more broadly reveals how school disinvestment policies influence risks of educational failure and other disadvantaging outcomes - including incarceration - in adulthood (Arum and Beattie 1999; Arum and LaFree 2008). Yet relatively little is known about how expanded incarceration - which increasingly includes parents -influences the educational outcomes of children (Cho 2009; Foster and Hagan 2007, 2009; Friedman and Esselstyn 1965; Stanton 1980; Trice and Brewster 2004). We argue that the intergenerational connection of parental incarceration to the educational outcomes of children is an underrecognized interinstitutional process linking prisons to schools in America.

More than half of state prisoners and nearly two thirds of federal prisoners are parents, and the number of imprisoned parents markedly increased from 1991 to 2007 (Comfort 2008; Glaze and Maruschak 2008; Mumola 2000). More than 2 million children, constituting about 3 percent of the U.S. population under 18 , have a parent incarcerated (Hagan and Dinovitzer 1999; Wakefield and Uggen 2010; see also Lynch and Sabol 2004; Murray and Farrington 2008; Rose and Clear 1998). We therefore examine in this article how incarceration may be a barrier not only for imprisoned parents but for the education of their children as well.

We give new attention to the educational fates of students who attend "high incarceration schools" - that is, schools with high proportions of incarcerated parents. Wakefield and Uggen (2010:400) insist that "conventional wisdom to the contrary, we can no longer think of prisoners as isolated loners or of the prison as isolated from other social structures." Parental incarceration is commonplace in many schools and may have significant intergenerational consequences for children (Sampson and Loeffler 2010). Clear (2007:102) emphasizes that "the potential negative impact of incarceration on school performance is particularly important," and there is growing evidence of the negative implications of paternal incarceration at the level of individual students (Foster and Hagan 2007). Research on imprisoned fathers builds on associations also observed between maternal incarceration and children's school problems (Cho 2010; Stanton 1980; Trice and Brewster 2004; cf. Cho 2009). These studies support the observation that mass imprisonment is a form of what Pager $(2003,2007)$ calls "marking" or "negative credentialing."

Yet we know little about further "spillover" implications of mass incarceration in America. Empirical research is developing on community contexts (Clear 2007; Sampson and Loeffler 2010), but studies that give attention to variation in mass incarceration across schools are rare (Cho 2011). Paternal incarceration is a mass American phenomenon, and as social scientists we should be looking for the contextual effects and collateral consequences of this penal policy for schools and children.

We know little about the mechanisms by which elevated school levels of parental imprisonment potentially impact children's educational attainments - even beyond the children whose own parents are incarcerated. Sharkey (2008:935) makes this point more broadly in 
observing how little we know about how collective neighborhood effects exercise their influence, remarking that "evidence on the mechanisms leading to the persistence of wealth and poverty across generations is still sparse" (emphasis in original). We ask in this article whether inequalities resulting from mass incarceration of parents flow through families and "spill over" through schools to increase educational inequality among the children of succeeding generations. Assessing the potential operation of this interinstitutional and intergenerational "prison through school pathway" is a step toward unpacking mechanisms of downward and blocked mobility in American society.

\section{INTERGENERATIONAL STUDENT AND SCHOOL EFFECTS OF IMPRISONING PARENTS}

High school environments form settings in which "defining moments" of failure or success can have long-lasting educational influences over the life course (Arum and Beattie 1999). Although there is a well-established literature on the effects of variations in conventional school contexts on educational outcomes (e.g., Cohen et al. 2009; Condron 2009; Kearney 2008; Raudenbush 1988), there is little or no empirical attention in this literature to the school-based contextual impact of parental incarceration on school environments as a potentially important interinstitutional and intergenerational source of disadvantaging educational outcomes.

Our expectation is that the contextual effect of the heightened aggregation and concentration of incarcerated fathers is extending beyond prison walls and families to the classrooms and schools where children are educated. When heightened levels of paternal incarceration are concentrated in schools and classrooms, they can create collective contextual ecologies that "spill over" beyond those who directly experience the parental incarceration. Drawing on Sharkey's (2008, 2010; see also Leventhal and Brooks-Gunn 2000) work on neighborhoods and children's cognitive performance, we suggest several perspectives from which to view school-level as well as individuallevel parental incarceration and the educational outcomes of children. Like Sharkey, our contribution is to assess the connection across generations between places - more specifically, schools - and persons - in our case, incarcerated fathers and their children. We similarly seek to assess the general hypothesis that the aggregation and concentration of incarcerated parents in particular school settings is associated with intergenerational limitations of educational mobility.

Sharkey's $(2008,2010)$ work connects with several perspectives specifying mechanisms that may also be involved in the interinstitutional and intergenerational prison through school pathway that we examine. The first perspective focuses on parent-child relationships and the absence of parent figures. The residential removal of the parent from the community is one mechanism of social disorganization identified with this perspective. However, more may be involved than the father's disappearance. Pager's (2007) concept of marking and negative credentialing adds to the residential mobility mechanism a related concern that a father's imprisonment creates a "marked absence" in socially stereotyped and social-psychological terms. So both mechanisms of residential mobility and stigmatic stereotyping may be involved in a father's incarceration.

Our thesis is that the implications of this mobility and marking extend beyond the incarcerated parent. Parent-child relationships play primary and formative roles in establishing connections within the family and set a foundation for building secondary relationships outside the family. W. J. Wilson (1996) and Anderson (1990) emphasize that the absence of fathers from communities as well as families compounds forces of both social isolation and stigmatization while further confining cognitive landscapes and perceived pathways to educational and other attainments (Sampson and Wilson 1995). Elder (1994) highlights the importance of parental relationships and figures outside the home in forming "linked lives" that establish and sustain educational and other kinds of transitions and trajectories in the movement from adolescence to adulthood.

High concentrations of incarcerated parents in schools may lead to the diminished capacity of disrupted families to monitor school attendance and nurture levels of school performance necessary to serve as stepping stones to higher education and as springboards to successful educational attainment. Teachers may regard children of incarcerated parents as having poor educational prospects and lower levels of competence (Dallaire, Ciccone, and Wilson 2010; Friedman and Esselstyn 1965). The difference, of course, is the scale at which these marked absences 
resulting from incarceration now occur in families, neighborhoods, and schools across America. The influence of paternal incarceration can flow both at the individual level within families and at the school level through teachers and among students who are influenced not only by their own father's incarceration but also by the spillover influence on the families of others. The absence of incarcerated fathers in this sense can individually and collectively mark children for educational as well as other forms of failure.

The second perspective on parental incarceration effects on children's educational achievement emphasizes reductions in economic and educational resources (e.g., Jencks 1972). These resources can both stimulate and support transitions and trajectories of educational achievement, and the absence of these resources can correspondingly weaken key links in educational trajectories. Again, the effects of the presence or absence of these resources can operate at both the individual and school levels. That is, these resources can have both individualized and collective expressions at the person and school levels.

Parents are thus a key resource that can elevate or diminish the collective efficacy of schools as socially supportive learning environments. The removal of imprisoned parents leaves single or surrogate caregivers with added parenting burdens, and in turn these single and surrogate parents can provide less assistance and be less of a presence in schools (Vacha and McLaughlin 1992). Clear (2007:102) theorizes that families disrupted by imprisonment increase the risk of family and student disengagement from school, whether resulting from the need to assume surrogate parenting responsibilities or the necessity to earn replacement income (see also McLanahan and Sandefur 1994; Trice and Brewster 2004; see also Casas-Gil and Navarro-Guzman 2002).

We incorporate a variety of measures of the economic and educational resources of individuals and schools in this article, for example, including not only a measure of the father's college completion and household income, but also the schoollevel proportion of college-educated fathers and a five-item factor-analyzed index of concentrated school-level socioeconomic disadvantage. These measures, and others indicated in the following, can capture spillover effects resulting from the collective advantages or disadvantages created by the clustering within schools of parents who have similar incomes and connected resources to invest in their children's educational environment.

A more abstract unifying perspective on the mechanisms that both Sharkey and Clear et al. propose in their related work on neighborhoods involves their broadened attention to weakened social ties, networks, and associations. For Clear et al. (2006:39) the problem is most prominently one of "coercive mobility" that takes persons from neighborhoods with results that reduce informal social controls on those who remain: "The theory, then, is that coercive mobility affects those who remain through networks of associations." Sharkey (2008:939) observes that "a general mechanism leading to continuity in the neighborhood environment is the set of ties, both social and psychological, that connect individuals to places." Neither Clear nor Sharkey directly measure these network ties of association, but both indirectly assess network assumptions about hypothesized relationships and resources operating in disadvantaged neighborhood outcomes.

Both the relationship and resource perspectives with their assumptions about network ties are further expected to unfold in their consequences over stages of the life course. Sharkey's (2008) analysis suggests that at the neighborhood or school level there is relatively limited variation in surrounding circumstances confronting students from childhood through adolescence and in the transition to adulthood. Thus, individual circumstances involving parental imprisonment may vary, but the collective circumstances of many schools and neighborhoods, especially in recent decades, have simply varied from bad to worse, exposing youth in these schools to increasingly and persistently unfavorable environments. The important additional implication of the focus on spillover effects is to call attention at the broader interinstitutional level of schools to the policy consequences for families surrounding those who have fathers incarcerated.

The model we explore depicts a multilevel and cumulative process of educational attainment. Similarly, Clear (2007:146) draws on his qualitative ethnographic field work to describe the family- and neighborhood-based interdependencies that are associated with paternal imprisonment and played out in neighborhoods and schools in ways that he emphasizes go well beyond the incarcerated parent.

Our participants described unparented children, unsupervised young people, and 
struggling single mothers as symptoms of incarceration, and these problems existed in abundance in their neighborhoods. The human capital of anyone who was dependent on a person headed to prison is damaged by their removal, and this damage was seen as systemic, especially in family life. The women and children who remain behind face uphill battles in sustaining a decent quality of life. The lack of a positive self-image and hopes for the future and unmanageable children who stopped going to school in intergenerational trouble with the law were seen as products of missing fathers and weak parental control. There was a sense in which our participants saw their whole neighborhood as marginally poorer, directly as a result of the large number of men who were occupying prison cells instead of living productive lives.

Our point is that the school settings located within these "high incarceration neighborhoods" (Sabol and Lynch 2003) form high-risk social contexts for adolescents who in any case struggle to make successful educational transitions to a stable adulthood. In sum, the effects of paternal incarceration in damaging educational trajectories of children may play out over the length of the life course and may be imposed through the environmental influence of families at the level of schools as much or more as within the families themselves.

However, it is essential to further acknowledge an alternative perspective that we must simultaneously take into account in assessing effects of the incarceration of parents: This alternative approach focuses on predisposing conditions of selection and self-control. This perspective indicates that exogenous processes predate and can account for endogenous correlations of paternal incarceration with intergenerational outcomes. More specifically, this perspective emphasizes that exogenous processes of selection and involving weak self-control make incarcerated parents, their schools, and their children different from parents, schools, and children with less or no imprisonment. That is, this selection and selfcontrol perspective argues that incarcerated parents, their schools, and their children have traits that predispose their fates and that these predisposing traits therefore account for the reduced educational attainments of these children. Of course, it is also plausible that selection and self-control variables are structurally and ecologically rooted, and so these variables are not necessarily only indicators of self-selection. This means our treatment of these variables as potential sources of spuriousness constitutes a conservative estimation of the impact of incarceration. We intend our treatment of these variables to provide a strong test of the influence of parental incarceration at student and schools levels.

The selection and self-control perspective comes in several forms. M. Gottfredson and Hirschi (1990) identify personally persistent and pervasive predispositions as low self-control that often results from ineffective parenting of children; J. Q. Wilson and Herrnstein (1985) refer to high impulsivity and low conscience with more ambiguous sources; while biological criminologists point to a physiological propensity for criminal offending perhaps resulting from low autonomic nervous system conditionability or biochemical imbalances (Fishbein 1990). While differing in their labeling of the predispositions, these formulations agree that a stable and versatile range of outcomes including parental imprisonment and school and child educational failure are products of common causes and resulting processes of self-selection. The result, as M. Gottfredson and Hirschi (1990:119) observe, is that "people ... sort themselves and are sorted [i.e., selected] into a variety of circumstances." We use a range of micro- and macro-level control$\mathrm{s}$-including self-reported delinquency, area crime rates and neighborhood drug problems, fathers with college degrees, school attendance levels, and further variables described in the following - to assess the self-selection hypothesis within the multilevel models we estimate.

Thus, we seek to assess whether the relationship and resource problems we emphasize operate beyond the effects of the alternative explanatory variables and putative selection processes just described. We are particularly focused in this article on demonstrating the robustness of the schoollevel association of paternal incarceration with children's educational attainments. In particular, if our multilevel interinstitutional perspective on intergenerational prison-school pathways is correct, we should find that the association of educational outcomes with school-level parental incarceration is statistically significantly independent of students' individual-level experiences of parental imprisonment and other parental risk factors 
that may lead to penal confinement. Our point is not to deny the influence of selection processes or economic and educational resources, but rather to take them into account while assessing the robustness of the association between paternal incarceration and the diminished educational outcomes of children.

\section{METHOD AND DATA}

We use the first four waves of the National Longitudinal Study of Adolescent Health (Add Health; Harris, 2009) and a supplementary collection of educational data from school transcripts - the Adolescent Health and Academic Achievement supplement to the Add Health survey (AHAA; Muller et al. 2007) - to assess the hypothesized school-level effects of parental incarceration on child educational outcomes. A major attraction of the Add Health study for this research is that it includes a large number of U.S. communities with extensive information collected on individual respondents, their parents, and their schools. The Add Health survey began in 1995 with adolescents sampled in a stratified design from grades 7 to 12 and nested within 132 U.S. schools (Harris et al. 2009; Udry and Bearman 1998; see also Resnick et al. 1997).

The Add Health research design ensures the national representativeness of this sample of youth who were in school in its first wave in terms of region of the country, urbanicity, school size, school type, and ethnicity (Harris et al. 2009). The study began with an in-school survey and then randomly sampled students from the schools who participated in the in-home survey. The inhome sample was followed longitudinally and had response rates of 78.9 percent at wave 1, 88.2 percent at wave 2, 77.4 percent at wave 3 , and 80.3 percent at wave 4 (Harris et al. 2009). In 1995 , or wave 1 , students at average age 15 were tracked for in-home interviews along with a parent, and adolescents were followed up at wave 2 in 1996. A third wave of data (20012002) followed up respondents at the average age of 21 years (ranging from 18 to 26 years of age), and a fourth most recent wave (2007-2008) again surveyed respondents at an average age of 27 years (ranging from 24 to 32 years old). Approximately 91 percent of wave 3 respondents signed a release form for collection of supplementary school transcript data (Muller et al. 2007).
Our analyses use information from the four wave in-home Add Health longitudinal sample and additional transcript information from the AHAA study.

We use hierarchical linear models (HLM; Raudenbush and Bryk 2002) to estimate variation in educational outcomes measured within and between the schools, with adjustments for nonindependence resulting from clustered sampling within schools through calculation of robust standard errors. We use the school weight at wave 1 as well as the longitudinal sample weight at Wave 4 . We present descriptive information about the variables used in this analysis in Table 1 and the appendix.

Nearly 15 percent of the Add Health youth reported in wave 3 that their biological fathers "had served time in jail or prison." In wave 4, the respondents more specifically reported how old they were when their biological fathers first went to jail or prison. To establish temporal priority, we considered fathers who had been in jail or prison between their children's birth and when they were 12 years of age. Overall, 6 percent of the respondents reported that before they were 12 years of age their fathers had been in prison or jail. If the father was incarcerated before the child's birth, and not after, he was placed in the comparison group with unincarcerated fathers.

We aggregated responses on this biological father incarceration question within schools to create a school-level measure of paternal incarceration: the proportion of fathers who had served time in prison or jail before their interviewed child's 12th birthday. This proportion ranged from 0 percent to 20 percent in the weighted sample. In other words, in some of the sampled American schools about a fifth of the fathers had experienced incarceration during the respondent's early childhood. By using reports at the individual level of paternal imprisonment and the schoollevel measure of paternal imprisonment, we can estimate separately the individual- and schoollevel associations of paternal incarceration with children's educational outcomes (cf. Crosnoe and Riegle-Crumb 2007).

We consider three measures of educational attainment: (1) high school grade point average (GPA) measured on a four-point scale from the AHAA component of the Add Health Study, (2) a wave 4 measure at the average age of 27 of educational outcomes on a 13-point scale from completion of eighth grade to postbaccalaureate 
Table I. Descriptive Statistics

\begin{tabular}{|c|c|c|c|}
\hline & M & $S D$ & Range \\
\hline \multicolumn{4}{|l|}{ School characteristics ( $n=122$ schools) } \\
\hline Biological father's imprisonment (ages $0-12$ ) & .07 & .04 & .0 to .20 \\
\hline School concentrated disadvantage & .05 & .71 & -1.05 to -1.77 \\
\hline Neighborhood drug problems & 1.49 & .24 & 1.14 to 2.16 \\
\hline Total crime rate (per 100,000 population) & $5,580.02$ & $2,801.75$ & .0 to $14,124.13$ \\
\hline School-level delinquency & 4.18 & .99 & 1.74 to 6.53 \\
\hline Proportion of fathers with college degree & .33 & .17 & .06 to .88 \\
\hline Average school attendance level & 4.19 & .90 & I to 5 \\
\hline School size & 2.08 & .72 & I to 3 \\
\hline Urbanicity of school ${ }^{\mathrm{a}}$ & .29 & - & 0 to 1 \\
\hline Public school ${ }^{b}$ & .91 & - & 0 to 1 \\
\hline Number of full-time classroom teachers & 55.44 & 32.97 & 5 to 182 \\
\hline Percentage of teachers with master's degree & 48.46 & 25.45 & 0 to 95 \\
\hline Proportion Hispanic & .17 & .19 & 0 to .92 \\
\hline \multicolumn{3}{|l|}{ Adolescent characteristics ( $n=4,745$ adolescents) } & 0 to .99 \\
\hline Cumulative grade point average & 2.68 & .81 & 0 to 4 \\
\hline Respondent's education level (wave 4) & 6.06 & 2.13 & I to 13 \\
\hline Respondent obtained college degree (wave 4) & .39 & - & 0 to 1 \\
\hline Biological father's imprisonment (ages $0-12$ ) & .06 & - & 0 to 1 \\
\hline Biological father has college education & .31 & - & 0 to 1 \\
\hline Biological father's alcoholism & .12 & - & 0 to 1 \\
\hline Perceived closeness with biological father & 4.40 & 1.09 & I to 5 \\
\hline Biological father smokes & .61 & - & 0 to 1 \\
\hline Delinquency (wave I) & 3.93 & 4.73 & 0 to 45 \\
\hline Gender $^{c}$ & .55 & - & 0 to 1 \\
\hline Single parent family & .15 & - & 0 to 1 \\
\hline Hispanic $^{d}$ & .13 & - & 0 to 1 \\
\hline African American & .16 & - & 0 to 1 \\
\hline Asian American & .06 & - & 0 to 1 \\
\hline Other & .02 & - & 0 to 1 \\
\hline Age & 15.20 & 1.57 & II to 20 \\
\hline Household income (wave I) & 49.67 & 42.26 & 0 to 870 \\
\hline Ever lived with father & .95 & - & 0 to 1 \\
\hline
\end{tabular}

Note: Reference categories are as follows:

a. urban $=\mathrm{I}$; suburban $/$ rural $=0$.

b. public $=1$; private $=0$.

c. female $=1 ;$ male $=0$.

d. Non-Hispanic white.

professional education, and (3) a wave 4 binary measure of college completion. The last measure specifically assesses the college/noncollege divide that has assumed growing importance in American society.

We considered a wide range of characteristics in addition to paternal incarceration as plausible additional influences on educational outcomes in our school-level analysis. We included access to a range of socioeconomic resources in an index measuring school-level concentrated disadvantage with five factor-analyzed items (with loadings between .6 and .9 and more fully described in the appendix) consisting of the proportion of households: (1) with incomes below $\$ 15,000$ and (2) $\$ 25,000$ according to census data, (3) in the lower quartile of incomes as reported by parents, (4) single parent families, and (5) black or 
African American families. We introduced as related measures of educational resources: the number of full-time teachers, the proportion of teachers with master's degrees, and public as contrasted with private school funding. We also included school-level measures plausibly reflecting the predispositions emphasized in the selection perspective on educational outcomes. For example, area crime rates, mean school level of self-reported delinquency, and neighborhood drug problems could be exogenous sources of both paternal imprisonment and reduced educational attainment. In addition, we also included measures of educational predispositions as indicated by the school-level proportion of fathers with college degrees, average daily school attendance, and the urbanicity of the schools.

To assess whether collinearity among the school-level measures might confound our results, we estimated models after removing highly correlated items from the school disadvantage scale (the correlation matrix and these models are available on request), and we estimated further equations that at the school level were reduced to include only father's imprisonment and proportion Hispanic and African American respondents along with the full array of student-level characteristics described previously (see Table 6).

We further included a wide range of variables at the individual level in estimating the aforementioned school-level effects. Perhaps most importantly, we controlled at the individual level for the father spending time in jail or prison before the child's age 12. We also included selection/predisposition measures of whether the father graduated from college, was alcoholic, and smoked. We further incorporated measures of whether the respondent ever lived with the biological father and the closeness as a child to the biological father. To parallel the school-level control for the selection/predisposition effects of area crime rate, we incorporated a self-report scale of delinquency at Wave 1 . We further included an individual-level predisposition measure of single parent family status, as well as indicators of age, gender, and race/ethnicity. As an indicator of family economic resources at the individual level, we included a measure household income.

We estimate joined individual and school-level HLM equations for the three educational outcomes, using linear hierarchical models for the GPA and highest educational level completed and logit estimates for college completion. For example, we first estimate an individual-level equation separately for students in each school in the Add Health study, resulting in regression coefficients (for each predictor) and an intercept term representing the student-input adjusted school outcome for each of the outcome measures (with the continuous predictors centered on their means) for each school. Our within-school modeling of the continuous GPA outcomes thus takes the following form:

$$
\begin{aligned}
& \text { Educational Outcome } i j= \\
& \qquad \beta_{0 j}+\Sigma \sum_{q=1} \beta_{q} X_{q i j}+\varepsilon_{i j},
\end{aligned}
$$

where $\beta_{O j}$ is the intercept; $X_{q i j}$ is the value of covariate $q$ associated with respondent $i$ in school-level $j$; and $\beta_{q}$ are the partial effects on the educational outcome of the school- and student-level explanatory variables. The error term, $\varepsilon_{i j}$, is the unique contribution of each individual, which is assumed to be independently and normally distributed with constant variance $\sigma^{2}$.

Second, we estimate the school-level equation in which the intercept terms for each school represent the dependent variable adjusted for student intake characteristics, and which we attempt to explain with school-level characteristics. This between-school equation thus takes the following form:

$$
\begin{gathered}
\beta_{0 j}=\theta_{00}+\theta_{01}(\text { paternal imprisonment }) \\
+\ldots+U_{0 j}
\end{gathered}
$$

where $\theta_{00}$ is school overall average educational outcome and $\theta_{01}$ is the regression coefficient of the effect of paternal imprisonment measured as a school-level mean score on overall school average educational outcome. The additional schoollevel covariate measures are as indicated previously. We standardized the preceding variables to place these school-level measures on a common metric. We tested for significant cross-level interactions with race/ethnicity (see Table 6). $U_{0 j}$ is the school-level error term, assumed to be normally distributed with a variance of $\tau$. Because the model parameters are initially estimated separately for each school, the input characteristics 
are not assumed to have a constant effect across all schools, and this allows the HLM modeling to provide a more accurate representation of the complex multilevel error structure.

\section{RESULTS}

We initially estimate student- and school-level models of father incarceration in Table 2. The first of these models in Panels A and B confirm the expectation that African American (Odds Ratio $[O R]=1.87, p<.01)$ but not Hispanic $(O R=$ $1.41, p>.05)$ students during their childhoods are significantly more likely to have fathers who are sent to jail or prison and that African American $(b=.13, p<.05)$ but not Hispanic $(b$ $=.08, p>.05$ ) youth are also significantly more likely to attend schools in which fathers are sent to jail or prison during the students' childhoods. The African American effects are reduced by introducing father's college education in the second models of Panels A and B, and at the school level this effect is reduced below statistical significance. However, being African American and having fathers without college education are both clearly associated with the risk of paternal imprisonment. This means that even if paternal imprisonment has similarly notable effects on the educational outcomes of both African American and other youth, the impact on African American youth will be broader because they are more likely to have fathers who are sent to jail or prison as well as to not be highly educated. These preliminary findings suggest the importance of exploring an interinstitutional prison through school pathway linking intergenerational outcomes.

We next use HLM 6.02 (Raudenbush et al. 2004) in Table 3 to estimate linear hierarchical models of student grade point averages cumulated from school transcripts at the end of high school. The intraclass correlation (ICC) from the baseline model in model 1 indicates 16 percent of the variance in GPA is between schools; this is reduced to 14 percent in model 2 with the introduction of the school-level measure of biological father's imprisonment before age 12. The addition of the school-level educational and economic resource measures of proportion fathers with college degrees and the factor scale of school concentrated disadvantage in model 3 reduces the ICC to 11 percent. Model 4 adds to the previous model all of the individual-level variables thought most likely to influence educational outcomes - in this case GPA - in addition to biological father's imprisonment.

A number of the respondents' individual-level characteristics in model 5 are predictive of GPA in the expected ways. Females $(b=.30, p<.001)$, Asian Americans $(b=.16, p<.05)$, youth perceived close to their fathers $(b=.03, p<.05)$, with fathers having college degrees $(b=.33, p$ $<.001)$, and households with higher incomes $(b$ $=.002, p<.001)$ all have significantly higher GPAs. In contrast, African Americans $(b=-.19$, $p<.001)$, having single parents $(b=-.10, p<$ $.05)$, with fathers who smoke $(b=-.16, p<$ $.001)$, and who self-report delinquency $(b=-$ $.03, p<.001)$ all have significantly lower GPAs. Beyond this, with all of these individuallevel independent variables taken into account, the children of fathers who spent time in jail or prison have significantly lower GPAs $(b=-.18$, $p<.05)$.

At the school level in model 5, net of the individual-level variables including father's incarceration, the school-level effect on average respondent GPA of biological fathers' incarceration is also negative and statistically significant $(b=-.07, p$ $<.05)$. Schools with higher concentrated disadvantage, drug problems, self-reported delinquency, and area crime rates are not significantly different in average GPA. The only school-level variable other than parental incarceration that is significant is average school attendance $(b=.10$, $p<.05)$, with school attendance increasing GPAs. The implication with regard to paternal incarceration is that not only are children of imprisoned fathers likely to receive lower grades, but as well, other youth who themselves do not have fathers who are incarcerated but nonetheless are in these schools with higher incarceration of fathers also receive lower grades net of all other variables thus far considered at both individual and school levels.

We next used HLM to estimate linear hierarchical models in Table 4 of the highest level of education completed, as reported in wave 4 of Add Health when the respondents were now an average of 27 years of age. The intraclass correlation from the baseline model 1 presented in column 1 for respondent's education level at wave 4 indicates 15 percent of the variance in this outcome is between schools. Adding paternal 
Table 2. Structural Predictors of Father's Imprisonment and the Student and School Level of Analysis

\begin{tabular}{|c|c|c|}
\hline \multirow{2}{*}{$\begin{array}{l}\text { A. Outcome: Father's imprisonment at student level }{ }^{\mathrm{a}} \\
\text { Hispanic }\end{array}$} & 1 & 2 \\
\hline & $\begin{array}{l}1.41 \\
{[.86-2.34]}\end{array}$ & $\begin{array}{l}1.23 \\
{[.74-2.05}\end{array}$ \\
\hline \multirow[t]{2}{*}{ Black } & $1.87 * *$ & $1.66 *$ \\
\hline & [1.23-2.86] & {$[1.09-2.52]$} \\
\hline Asian & $\begin{array}{l}.38 \\
{[.14-1.02]}\end{array}$ & $\begin{array}{l}.42 \\
{[.16-1.12]}\end{array}$ \\
\hline Other ${ }^{b}$ & $\begin{array}{l}.92 \\
{[.32-2.65]}\end{array}$ & $\left.\begin{array}{l}.86 \\
{[.29-2.51]}\end{array}\right]$ \\
\hline Biological father has college education & & $\begin{array}{c}.20 * * * \\
{[.12-.33]}\end{array}$ \\
\hline Wald statistic & $3.37 *$ & $13.62^{* * *}$ \\
\hline \multicolumn{3}{|l|}{ B. Outcome: Father's imprisonment at school level ${ }^{c}$} \\
\hline Proportion of Hispanic students $(\mathrm{std})^{\mathrm{d}}$ & $\begin{array}{l}.08 \\
(.07)\end{array}$ & $\begin{array}{l}.02 \\
(.07)\end{array}$ \\
\hline Proportion of African American students (std) ${ }^{d}$ & $\begin{array}{l}.13^{*} \\
(.07)\end{array}$ & $\begin{array}{l}.12 \\
(.07)\end{array}$ \\
\hline Proportion of fathers with college degree & & $\begin{array}{l}-.25 * * * \\
(.07)\end{array}$ \\
\hline Constant & $\begin{array}{l}-.05 \\
(.07)\end{array}$ & $\begin{array}{l}-.05 \\
(.07)\end{array}$ \\
\hline$R^{2}$ & .02 & .11 \\
\hline F statistic & 2.45 & $6.22^{* * *}$ \\
\hline
\end{tabular}

a. Logistic regression model.

b. Reference category: Non-Hispanic white.

c. Ordinary least squares regression model.

d. Standardized variable.

incarceration at the school level reduces the ICC to 8 percent. Adding further school predictors, the ICC is reduced to 4 percent.

Model 4 again includes all of the individuallevel variables and the baseline set of school-level variables considered in the comparable model of the previous table. These variables again include the individual- and school-level measures of biological father's incarceration before respondent's age 12. Again, the incarcerated father variable is negative and significant as a predictor of achieving higher educational levels at both the individual $(b=-.39, p<.001)$ and school levels $(b=-.30, p$ $<.05$ ). Beyond this, there are some similarities and differences with the GPA models in the previous table. At the individual level, females $(b=.56$, $p<.001)$, fathers having college degrees $(b=.96$, $p<.001)$, and household income $(b=.01, p<$ .001 ) repeat as positive individual-level predictors of achieving higher education levels, while selfreported delinquency $(b=-.04, p<.001)$ is again a significantly negative predictor of higher education. Several other individual-level variables are now nonsignificant, although generally signed in the same direction as previously.

A number of new effects appear at the school level in model 5 for highest education level achieved. Proportion of fathers with college degrees $(b=.19, p<.05)$ now has its expected positive effect on achieving higher education. While father incarceration is slightly reduced at the school level, it retains high statistical significance $(b=-.27, p<.001)$. Beyond this, number of full-time teachers $(b=.18, p<.05)$ and teachers with master's degrees $(b=.12, p<.05)$ are positive predictors of higher educational levels.

We also include a sixth model in Table 4 that incorporates the further mediating influence of high school GPA on the level of higher education achieved $(b=1.21, p<.001)$. Controlling for GPA also reduces by more than half and below statistical significance the individual-level effect of father's imprisonment $(b=-.39, p<.05$ to $b=-16, p>.05)$. High school GPA is 


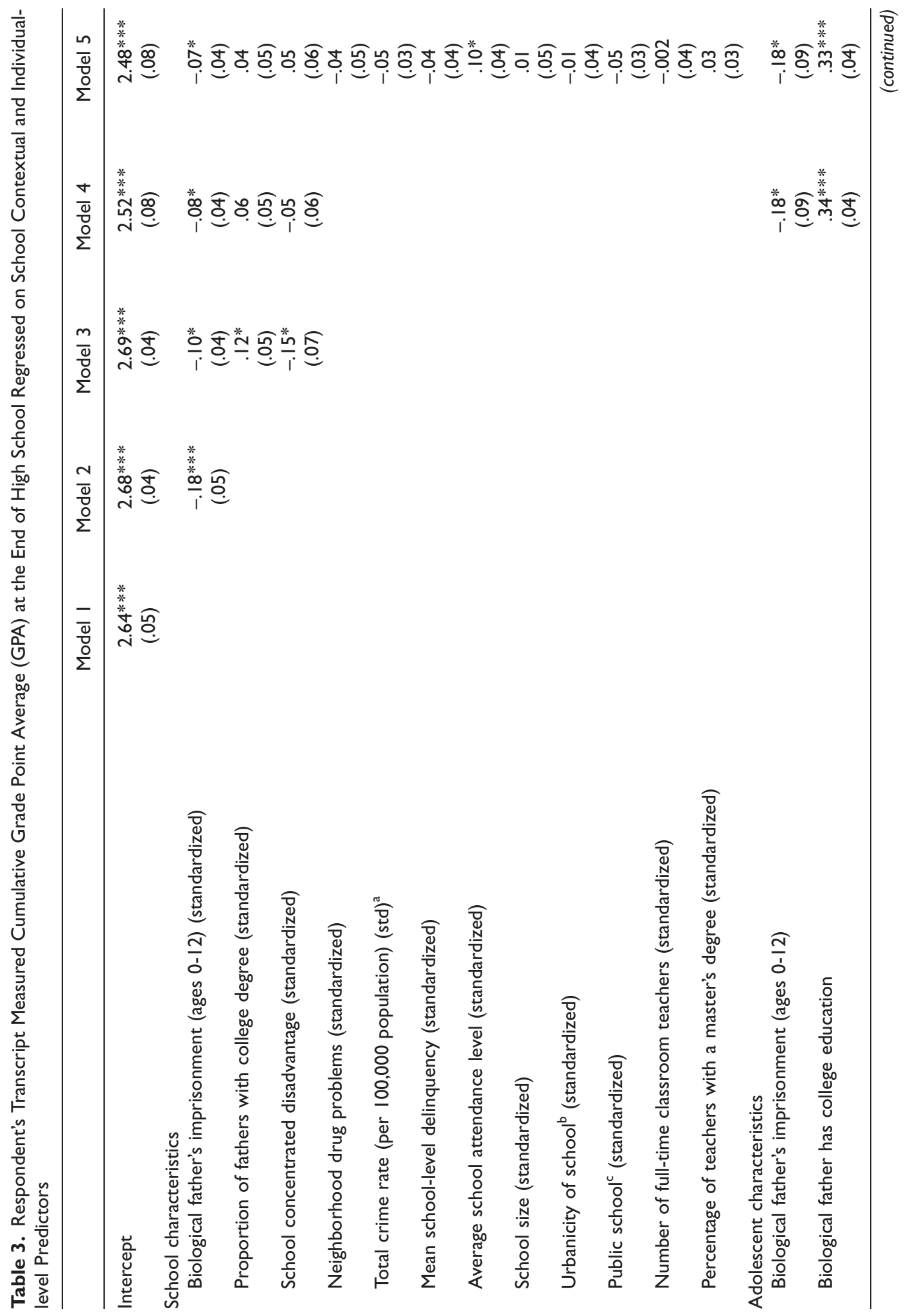




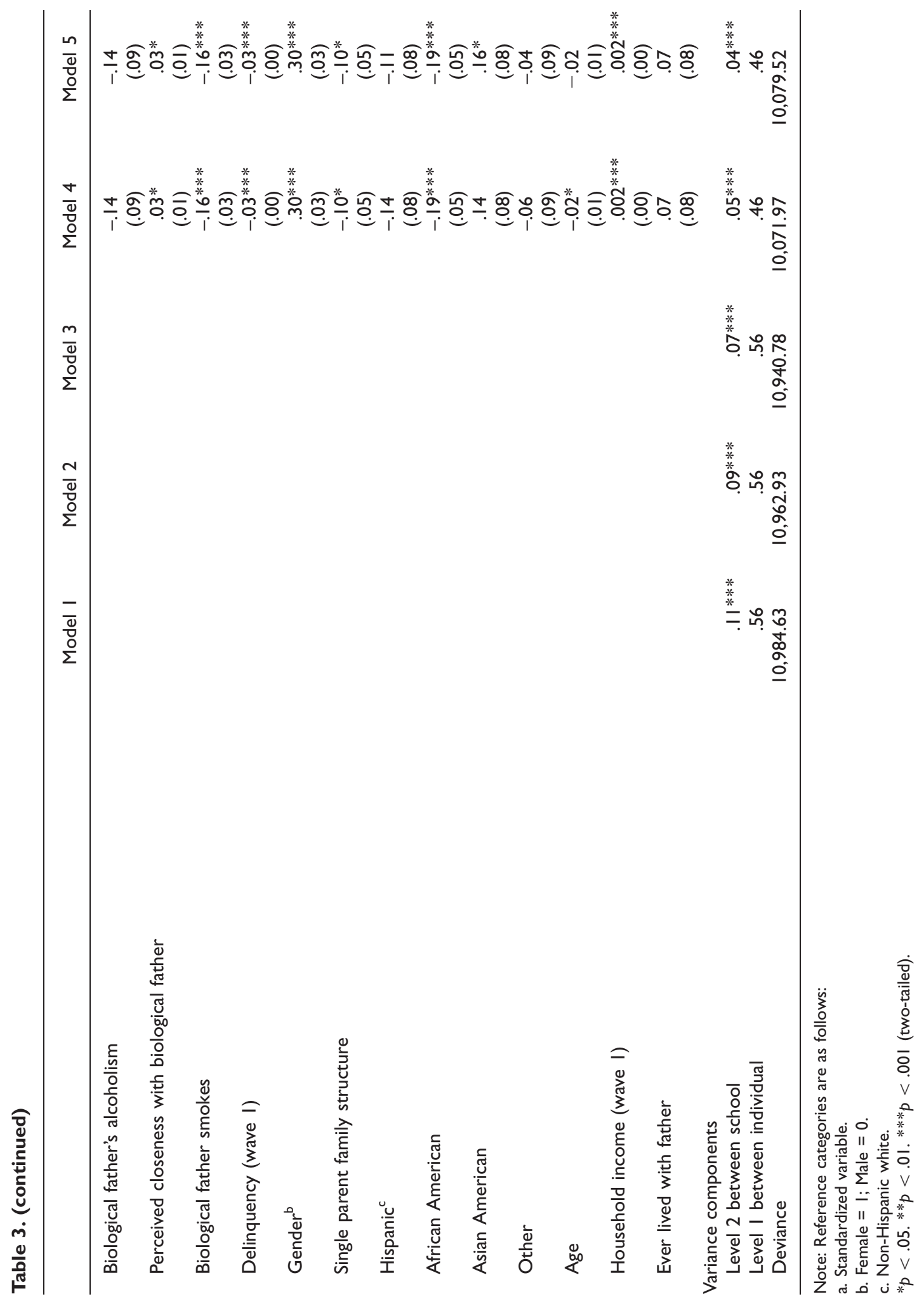




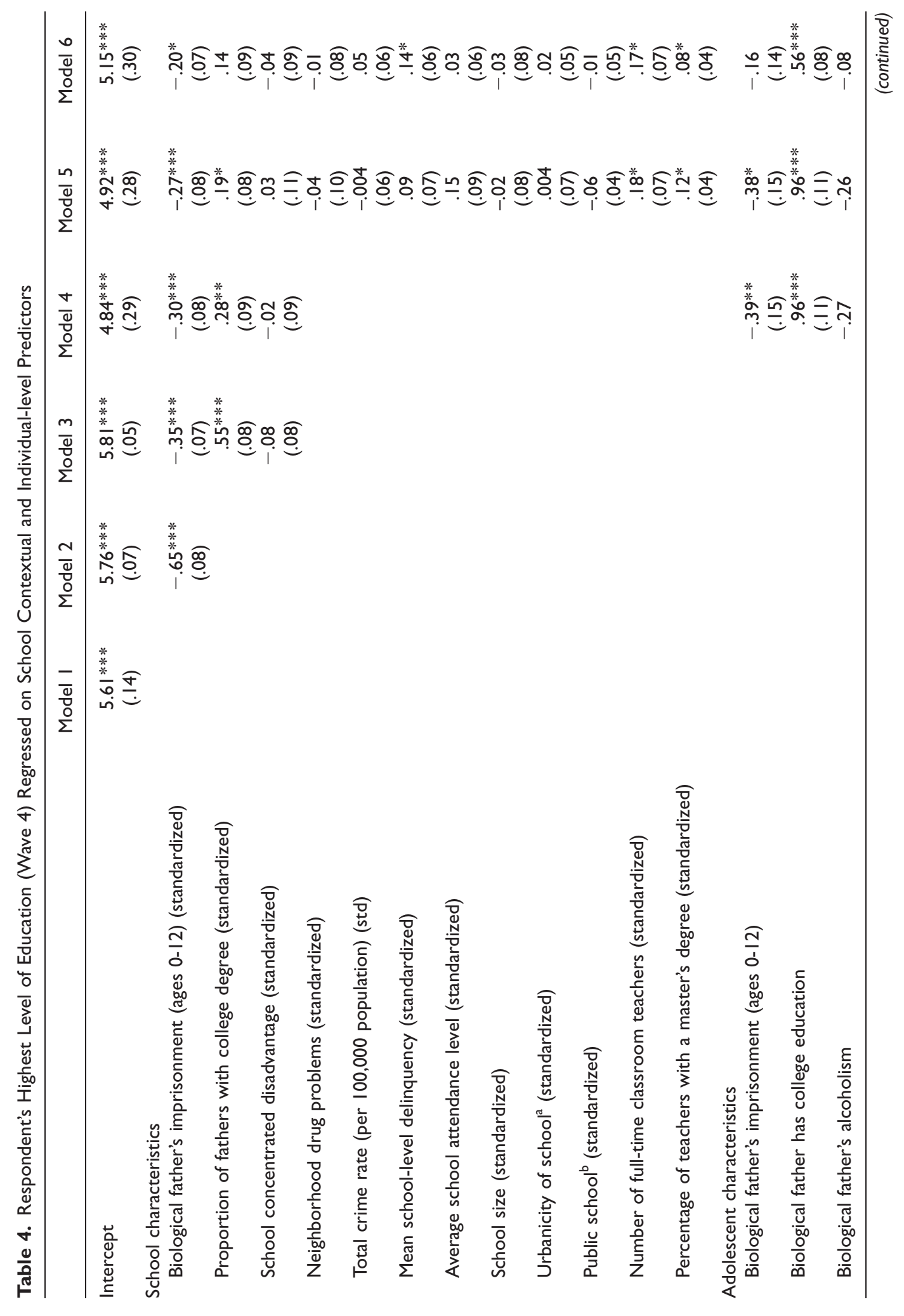




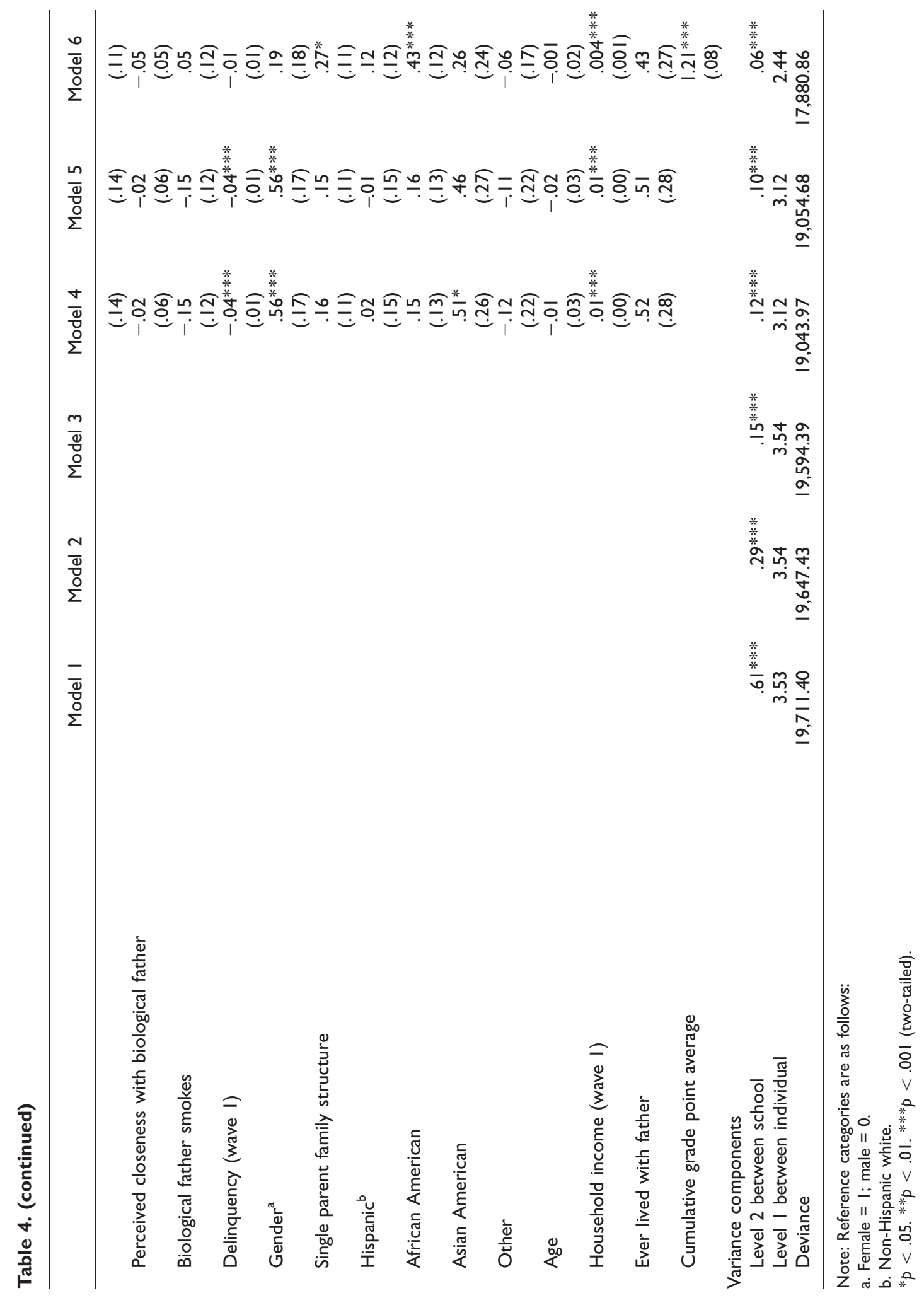


a predictably powerful and long-term mediator of the level of education achieved in adulthood, reducing the effect of the school-level proportion of fathers with college degrees by about a quarter and below statistical significance (from $b=.19, p$ $<.05$ to $b=.14, p>.05$ ). Nonetheless, the school-level effect of father incarceration remains robust and significant: High school GPA reduces the macro-influence of biological father's incarceration by about one third (from $b=-.27$ to $b=-.20, p<.01)$. It is striking that the schoollevel effect of father incarceration on average level of education completed remains highly significant in the face of controls for a wide range of independent variables and high school GPA. Controlling GPA actually increases the effects of being African American $(b=.43, p<.001)$ and the child of a single parent $(b=.27, p<.05)$, while reducing the effect of father's college education by almost half (from $b=.96$ to .56 ).

The robust influence of the school level measure of father incarceration is also apparent in the hierarchical generalized linear models (HGLM) of earning a college degree summarized in Table 5. Again with college degree as the outcome in models 4 through 6 , father incarceration is persistently significant - at the individual $(b=$ -.79 to $-.85, p<.05)$ and school levels $(b=-$ .39 to $-.38, p<.001)$ - than all other variables except father's college education $(b=1.27$ to $1.06, p<.001)$ and respondent's GPA $(b=$ $2.23, p<.001)$. The further results in the five models summarized in Table 5 are similar to findings in the previous tables.

The individual- and school-level influences of father incarceration are among the most reliably and persistently apparent findings across the educational outcome measures - GPA, highest education level completed, and college degree - across the three tables. The mediating role of GPA is also apparent in the latter two tables, although as perhaps should be expected, high school GPA is less important mediator of college graduation than in the previous table, which includes the fuller range of postsecondary outcomes. The influence of other variables is largely as expected. The most striking finding is the repeated impact of father imprisonment, both at the individual level and beyond at the school level of influence. There is consistent evidence that father incarceration not only operates in a long-lasting way, but also in a diffused way in high incarceration schools beyond the immediate family on other surrounding children as well.

Table 6 provides a sensitivity check for all three educational outcomes of possible collinearity effects of including several moderately to more highly correlated measures in the concentrated school disadvantage scale and among the other school-level variables in Tables 3 through 5. This table also reports tests for cross-level interaction effects of the school-level measures of biological father's incarceration with the race/ ethnicity of the respondents. At the school level, we have included only the proportion of biological fathers incarcerated and the proportions of Hispanic and African American students in the schools, while at the student level we have included the race/ethnicity of the respondents and all the other student-level variables (although the latter coefficients are not presented to conserve space). In the top part of Table 6 , we see that at the school level, the effects of father's incarceration on the respondent educational outcomes are almost identical to those presented for this variable in Models 1 and 5 of Tables 3 through 5, indicating these results are insensitive to possible collinearity problems at the school level. In the lower part of Table 6, we see that none of the cross-level interactions with race/ethnicity are statistically significant. The latter null findings indicate that while African American youth are more broadly impacted by having fathers imprisoned - because at both the student and school levels more of their fathers are imprisoned - the impact of race and paternal incarceration is additive rather than multiplicative.

We provide a further indication of the impact of parental incarceration on educational outcomes by, respectively, using the final main effects models in Tables 3, 4, and 5 to predict GPA, highest level of education attained, and college completion. We predict these outcomes under conditions that vary by whether a parent is incarcerated before age 12 and alternatively attending a high school with averaged upper or lower quartile levels of parental incarceration. The predictions are comparable in that the same remaining independent variables are included across the models and set at their mean values. Thus, for comparability, the prediction models used from Tables 4 and 5 exclude the mediating role of GPA for the highest educational level attained and college completion. 


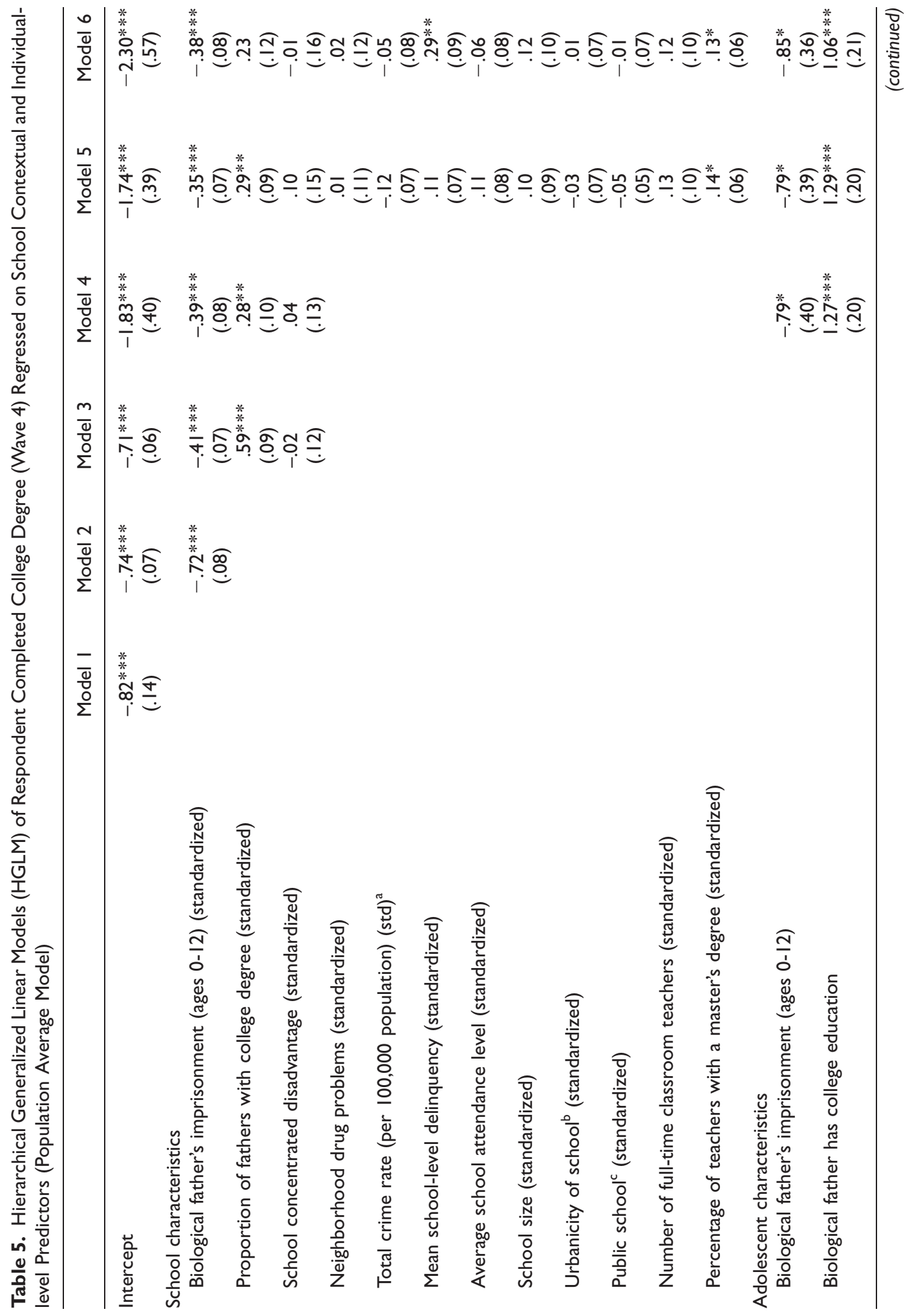




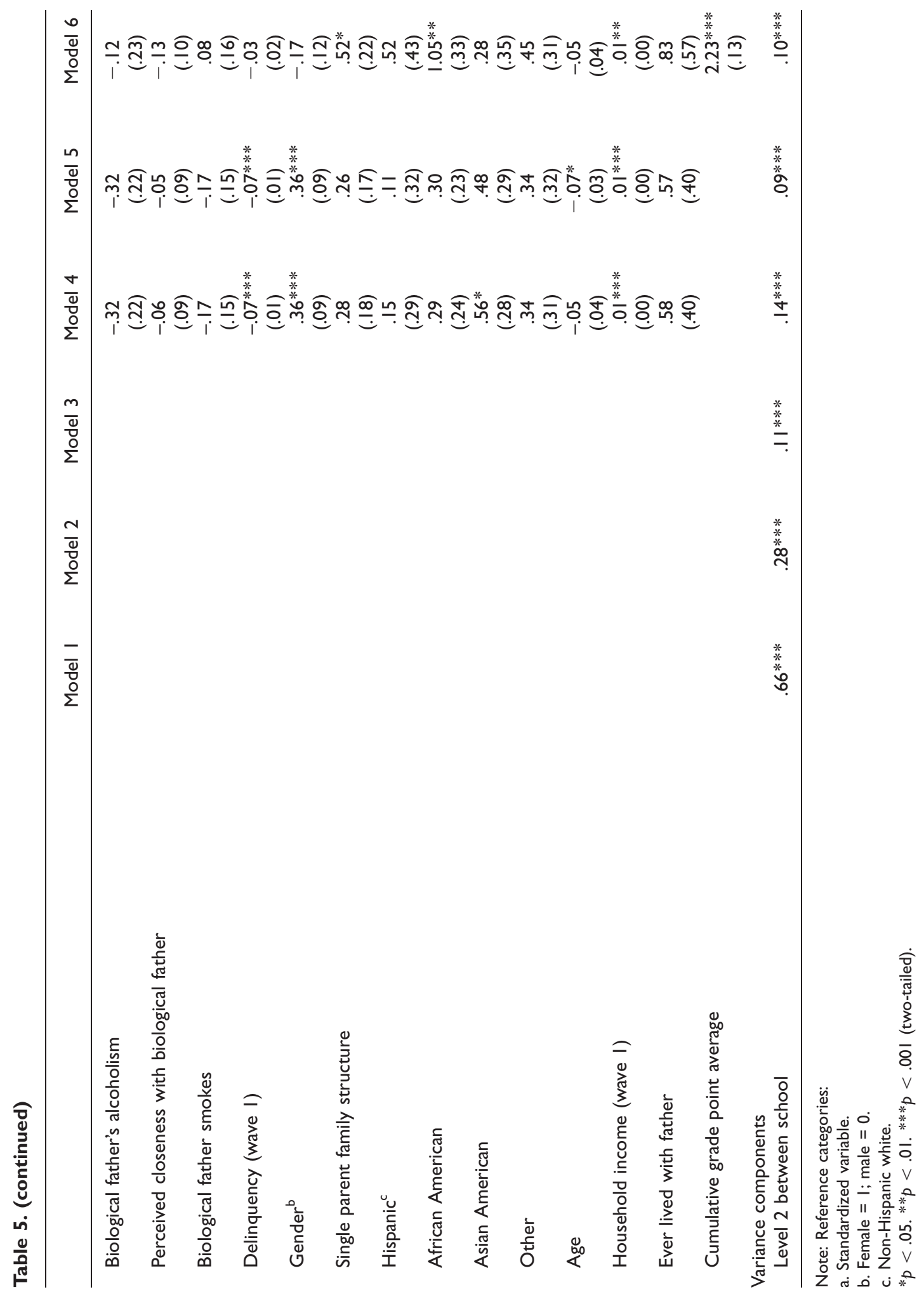




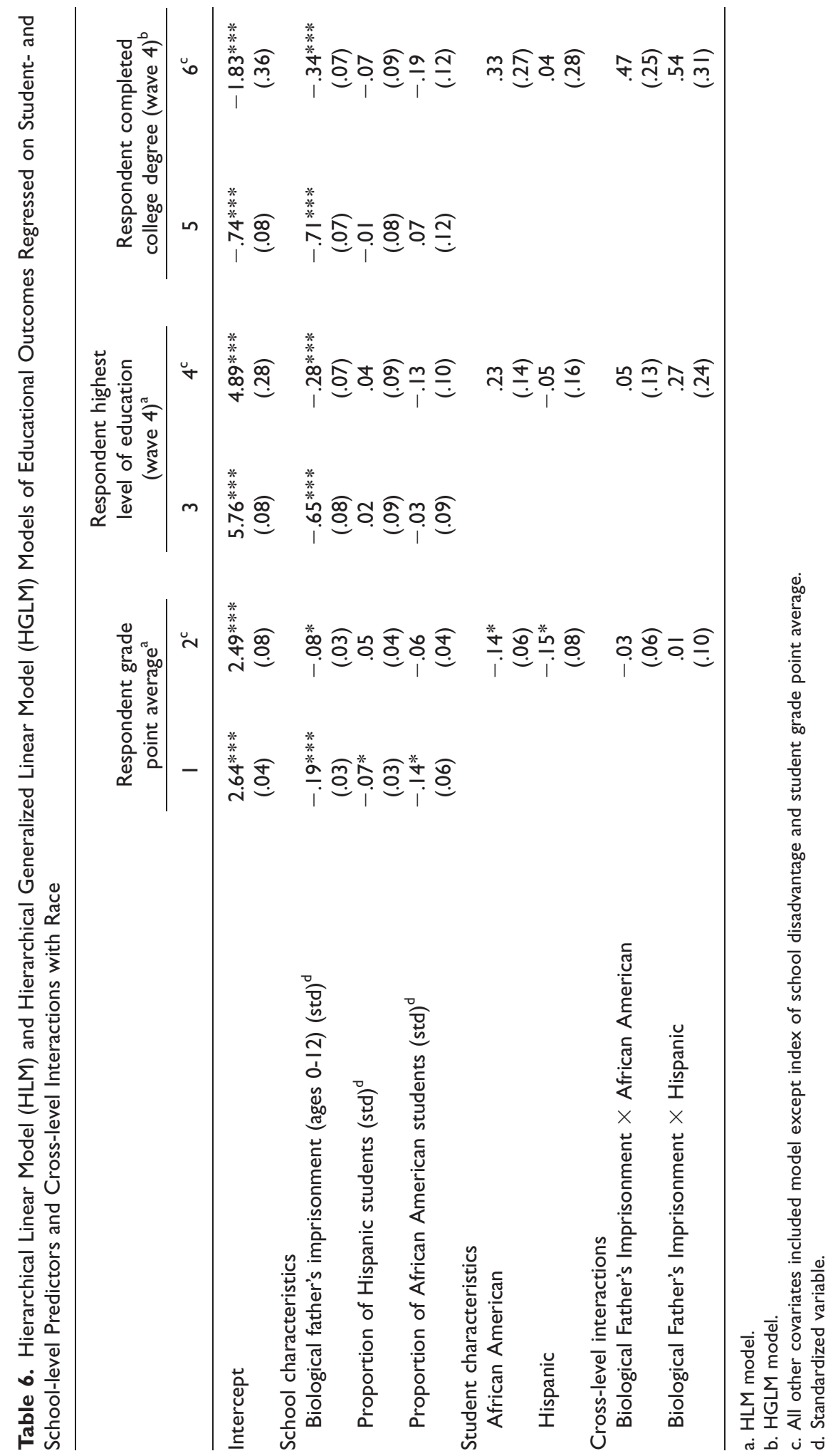


Although the bar graphed patterns are similar across the three outcomes, the disparities in outcomes are perhaps most apparent in Figure 1C for college completion. School incarceration effects are apparent for both sets of bars in Figure 1C. More than 40 percent of the youth without a biological father incarcerated before age 12 who attend a school with only 2.5 percent parental incarceration complete college. Yet just over 25 percent of the youth without a biological father incarcerated before age 12 who attend a school with 13.4 percent parental incarceration complete college. This is about the same level of college completion for youth who attend a school with only 2.5 percent parental incarceration but who have a biological father incarcerated before they are 12 . Finally, only about 12.5 percent of the youth with a biological father incarcerated before age 12 and attending a school with 13.4 percent parental incarceration complete college. Thus, the combined result of having an incarcerated father and attending a school with a relatively high rate of paternal incarceration is to reduce college completion by about three quarters, from 40 percent to 10 percent.

\section{COLLATERAL DAMAGE OF PATERNAL MASS INCARCERATION}

The mass incarceration of American parents has grown to the point that more than a fifth of the fathers at highly affected schools have already spent time in jail or prison by the end of their child's primary school education. Our results indicate that concentrated incarceration of parents in school populations is negatively and significantly associated with the educational attainment of children. Most notably, we demonstrate that students at schools with higher levels of paternal incarceration have limited access to the levels of academic accomplishment increasingly required to succeed in America. These findings expand the perspective that childhood and adolescent school experiences are defining mediating moments in the life course (Arum and Beattie 1999). The net negative school-level association we have observed of paternal imprisonment with educational attainment persists even after we introduce both schooland individual-level mediating processes and extraneous or selective predispositions into our analyses. Parental incarceration is an increasingly impermeable barrier between college- and noncollege-bound youth in America.

These results are supportive of prior theoretical and empirical work indicating a link between parental incarceration and children's educational outcomes (Cho 2010; Foster and Hagan 2007, 2009; Friedman and Esselstyn 1965; Stanton 1980; Trice and Brewster 2004). However, this analysis differs in establishing that the net association of negative educational outcomes with the school-level concentration of paternal incarceration in the aggregate, or in other words, the mass incarceration of fathers "spills over" to youth beyond the children of incarcerated fathers. This study provides evidence of an interinstitutional prison through school pathway of intergenerational influence of fathers on children in America.

We have considered three perspectives on effects of paternal incarceration on the educational attainments of children that focus on the residential mobility and stigmatic stereotyping involved in the interruption of parent-child relationships, the availability of educational and economic resources, and the selection of parents and children into imprisonment as well as neighborhood school settings where imprisonment is common. Our findings are to varying degrees consistent with all three of these perspectives and we must await further research to better distinguish the alternative mechanisms implied by them. We have placed our emphasis on the net negative association-beyond measured resource and potential selection differences - observed at both the student and school levels between paternal incarceration and educational outcomes. We have suggested that paternal incarceration results not only in removal from the community, but is furthermore a form of "marked absence" that predicts consistently negative outcomes at student and school levels across the three educational measures we have considered.

Pager $(2007$, p. 4) describes the marking process of imprisonment as creating a form of negative credential: "The 'credential' of a criminal record, like educational or professional credentials, constitutes a formal and enduring classification of social status, which can be used to regulate access and opportunity across numerous social, economic, and political domains." Wakefield and Uggen (2010) similarly suggest 


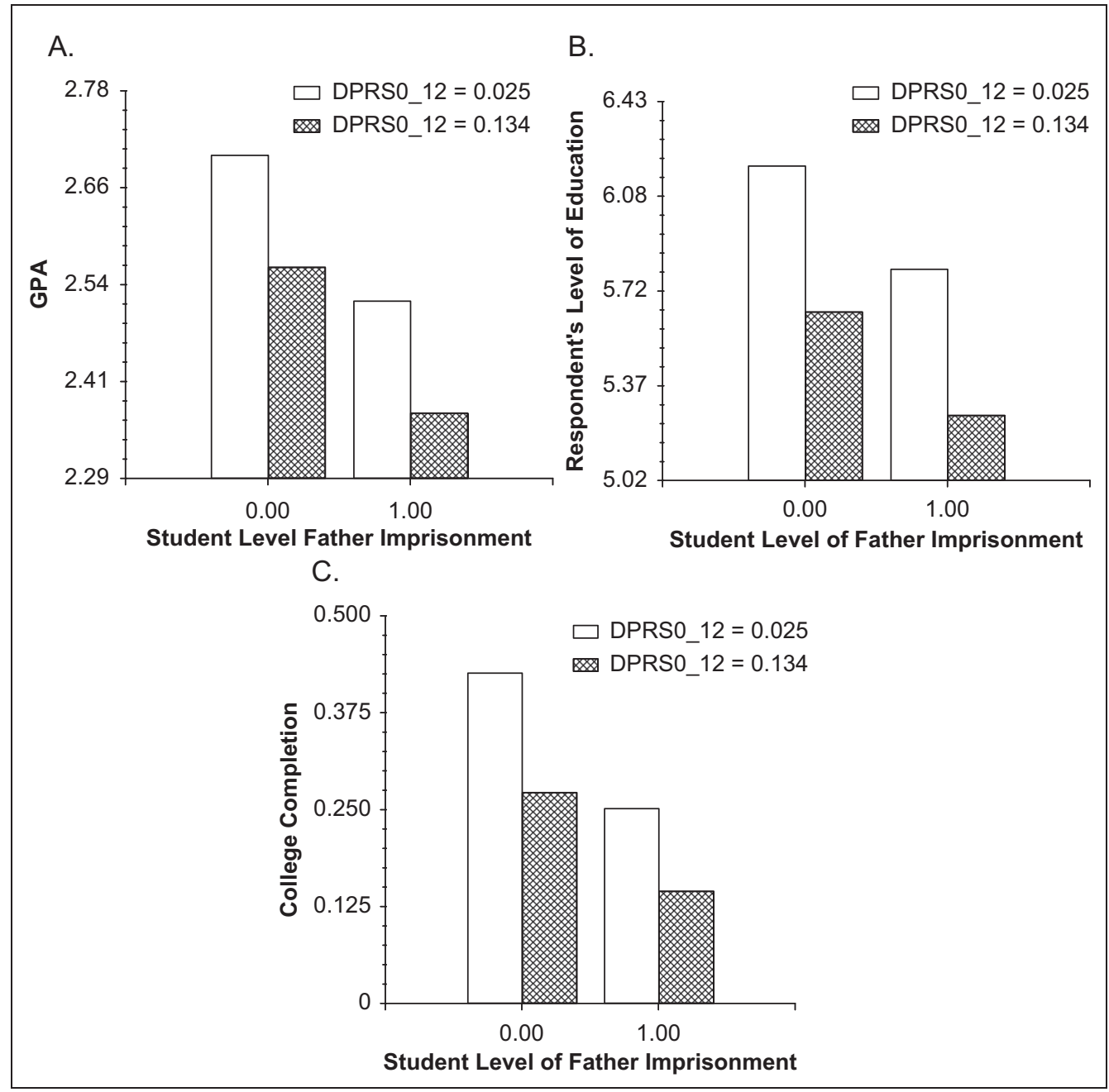

Figure I. Cumulative grade point average (GPA), respondent's education level, and college completion as a function of father's imprisonment

Note: DPRSO_12 corresponds to averaged lower and upper quartiles on school-level proportion of father imprisonment.

that current and former prisoners have emerged as a distinct Weberian status group, with the prison now assuming a place as a major stratifying institution in American society that is altering life chances in myriad ways that go to the heart of stratification research. Comfort (2008) calls the children of incarcerated parents "legal bystanders" who are drawn within the perimeter of the effects of the legal system through the actions of others. It is important that we further understand the interconnections of imprisoned parents, "fragile families," and underresourced schools in the educational process (Western, Lopoo, and McLanahan 2004). This understanding requires attention to the changing American context in which these connections are unfolding.

It is important to acknowledge that some of the most severely marked youth (cf. Hagan and McCarthy 1998) may not be represented in the school sample used in this research, even though the Add Health survey is designed to be nationally representative. The youth in the Add Health panel study we have analyzed were born and raised before, during, and after the surge in drug-related 
violence that devastated America's racial ghettoes. The first two waves of the Add Health study were conducted in 1995 and 1996 when these youth were in their teens and crime rates in America were receding. Yet imprisonment was continuing its steep ascent. Mauer's (2009) recent research reveals that this was a period of massively concentrated and race-laden but also ultimately declining imprisonment of blacks for drug crimes, combined with still increasing imprisonment for whites (see also Oliver 2008). Mass imprisonment policies in America began in the 1990s to equalize the racial risk of imprisonment - but at the collateral cost of raising imprisonment in the aggregate. This may have contributed to a generic impact our analysis suggests of the mass imprisonment of fathers on African American and other youth. Nonetheless, it remains the case that during the longer period covered by the Add Health panel, African American fathers were much more likely than other fathers to be incarcerated, so the African American youth in the sample were more broadly impacted than other youth by paternal incarceration (i.e., in simple additive if not multiplicative terms) (see also Wakefield and Wildeman 2011).

D. Gottfredson (2001) makes the potentially important point that the size of the kind of school effects we have observed are likely underestimated to the extent that relevant variation exists within school micro-environments. She observes that, "Schools contain important microenvironments, the most important of which is probably the classroom. If the classroom effects offset one another, estimates of school effects will be relatively meaningless averages of these more potent effects" (p. 81). While these effects are unlikely to be completely offsetting, it is potentially important to think about the extent to which streams of classes within schools, and smaller groupings of peers within these streams, bring imprisonment effects into schools and surrounding settings. It is likely in selected tracks and streams of inner-city high schools in America that the fathers of more than half of the youth have been incarcerated.

We suggest that future research should focus on the role of classroom teachers in what Pager has called the marked and negative credentialing process. There is potentially important experimental evidence that what we have called the marked absence of an incarcerated parent can impair teacher-student relationships in schools. Dallaire et al. (2010) randomly assigned scenarios to teachers describing a female student whose mother was imprisoned. They found that the teachers in their experimental treatment group rated these students as less competent than teachers in a control group in which the child's mother was described as being away for other reasons. Further research could usefully test whether this effect is limited to incarcerated mothers and daughters and whether this effect is additionally influenced by variation in surrounding school incarceration levels.

The broad-ranging intergenerational school effects of mass incarceration observed in this research indicate that the "long arm of the law" reaches far beyond the jails and prisons where inmates are held, with harmful collateral consequences for educational outcomes that extend more broadly across the geographic and temporal landscape of the national American sample we have examined. 


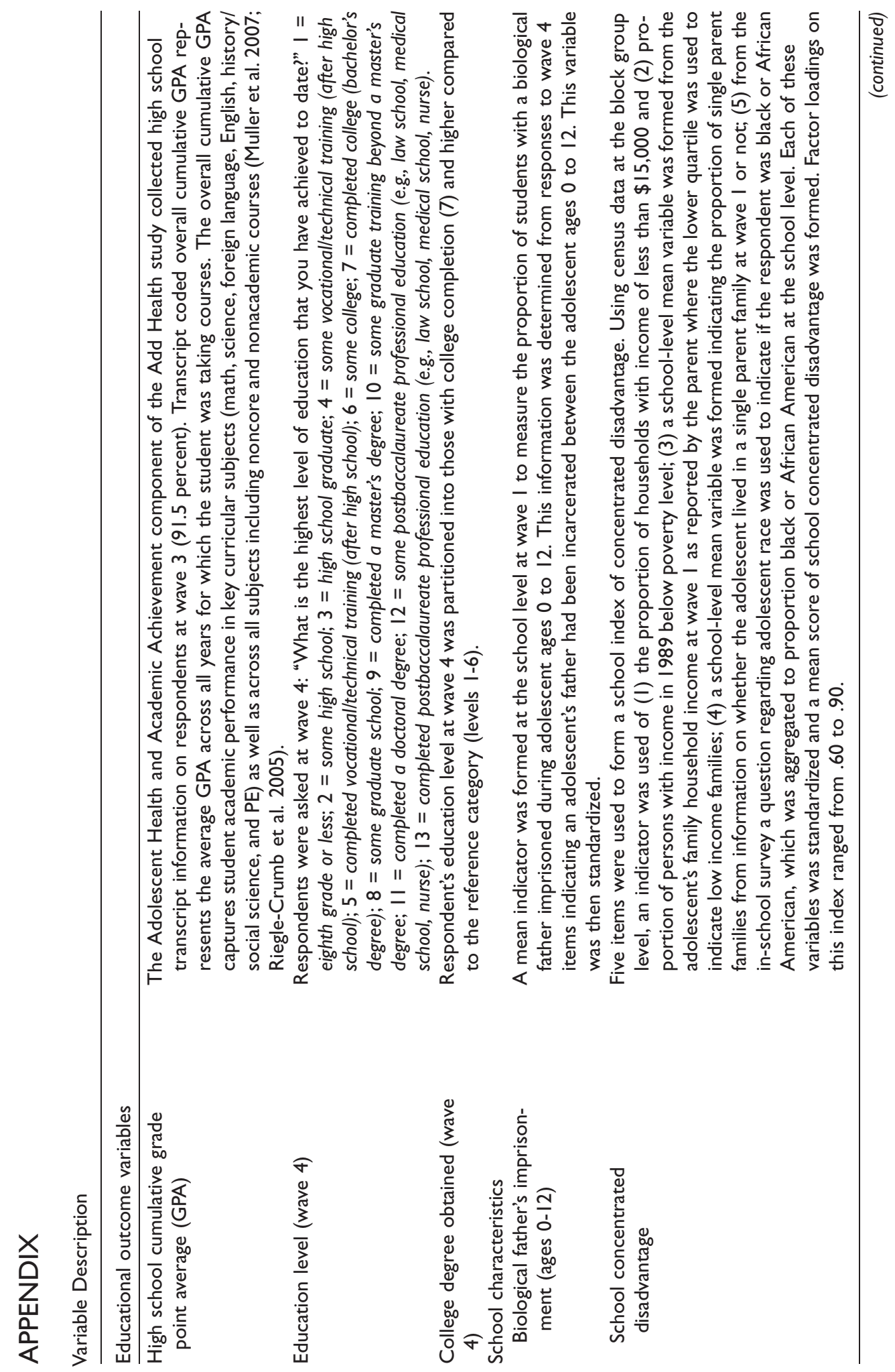




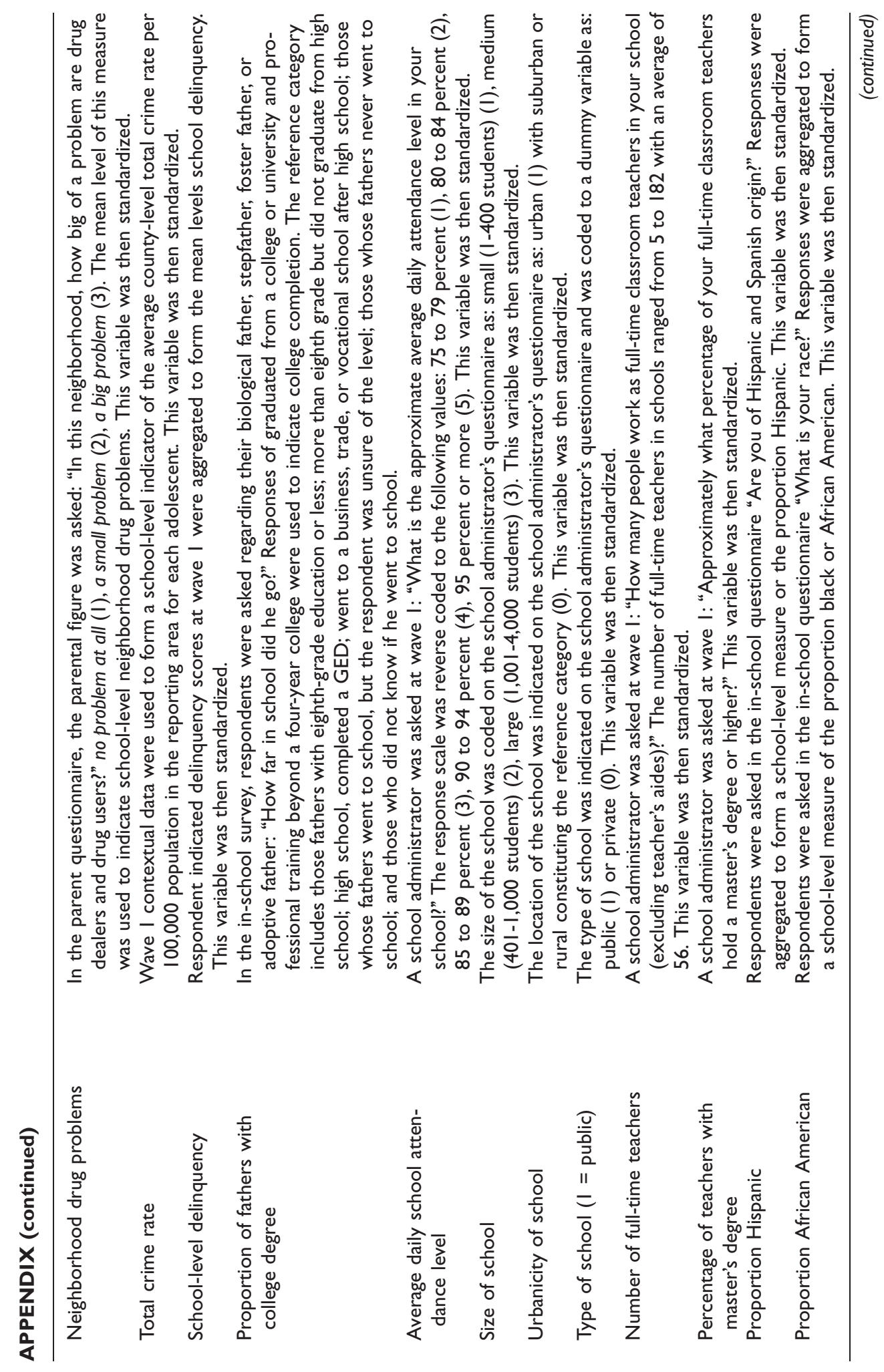



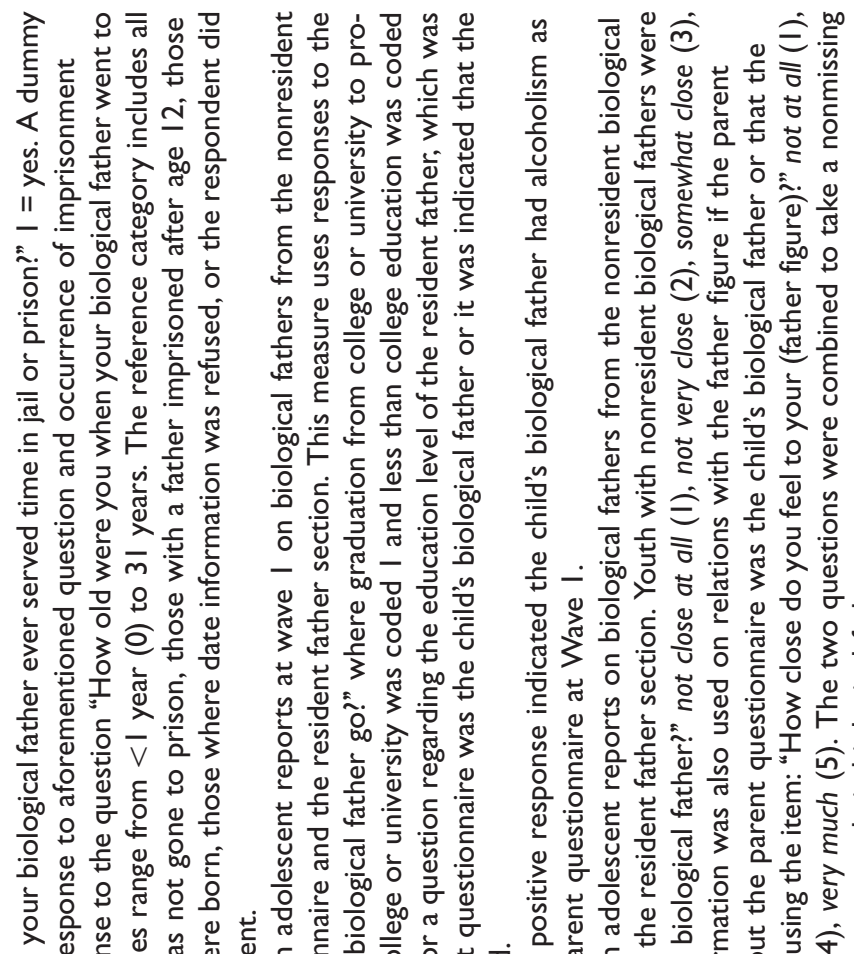

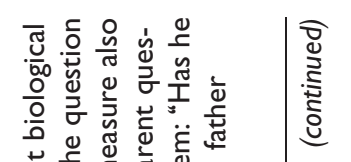

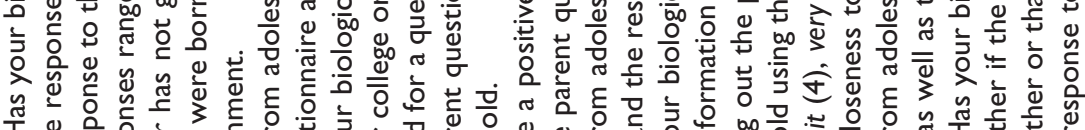

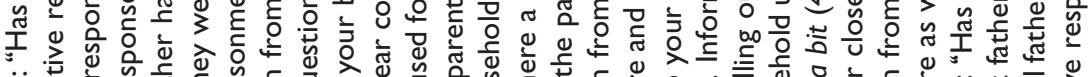

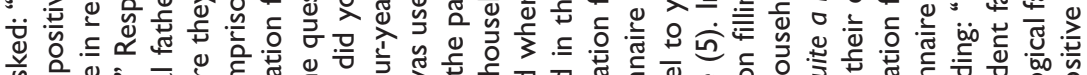

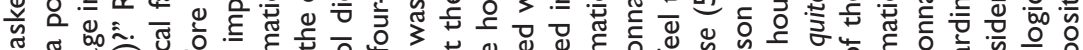

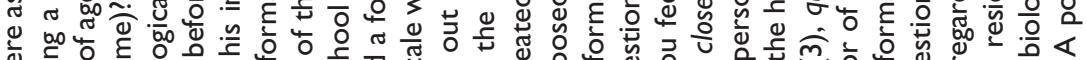

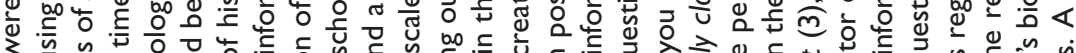

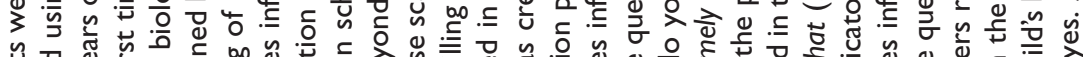

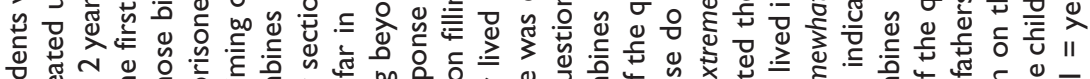

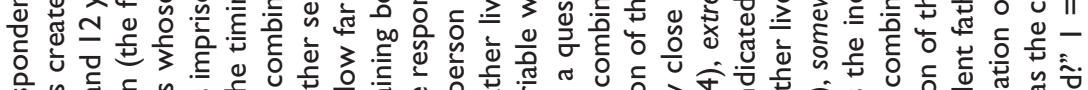

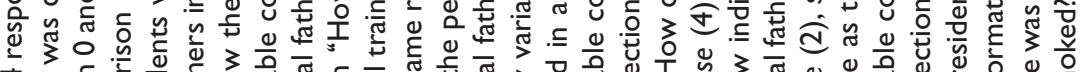

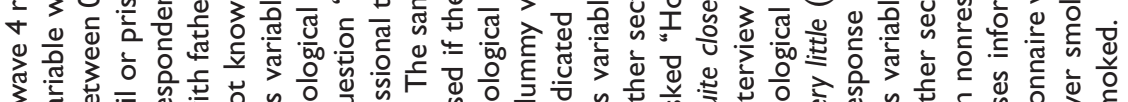

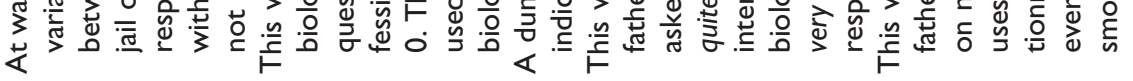
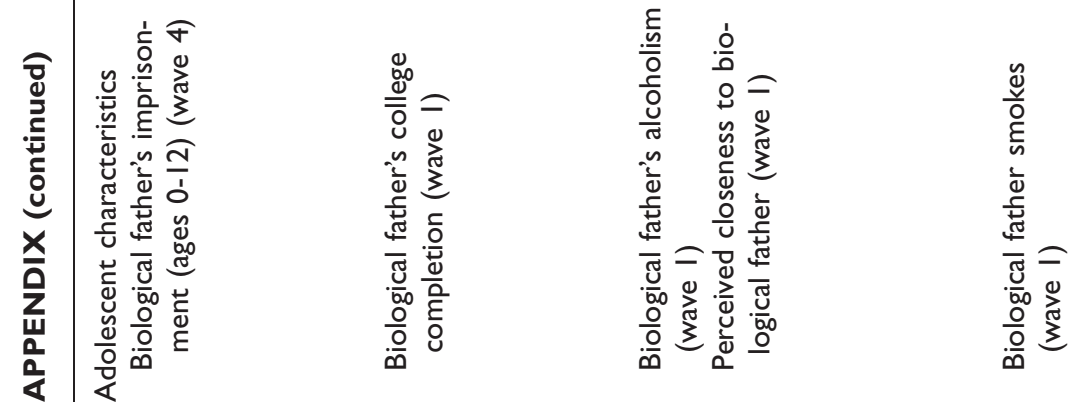


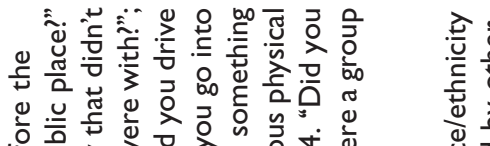

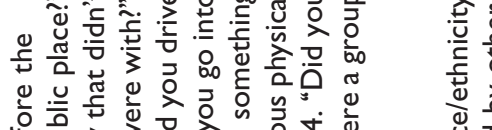

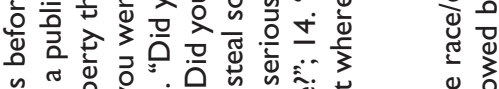

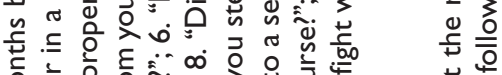

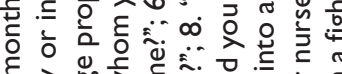

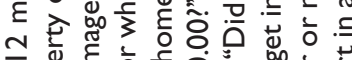

势

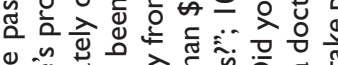

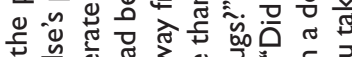

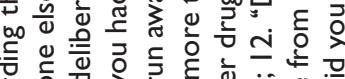

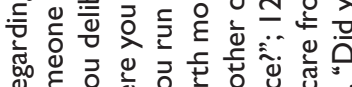

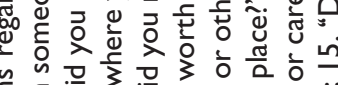

产

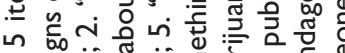

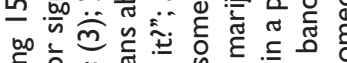

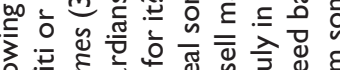

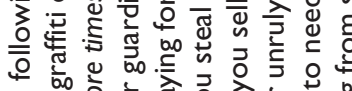

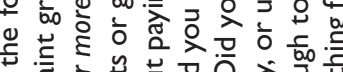

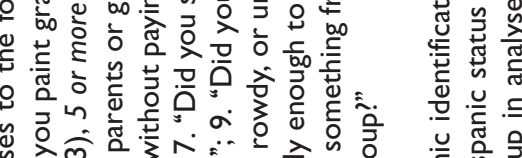

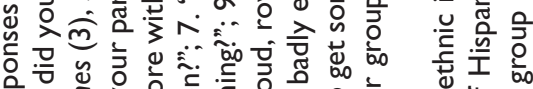

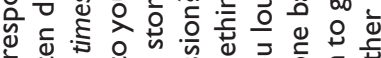

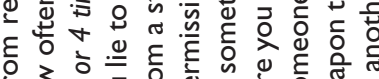

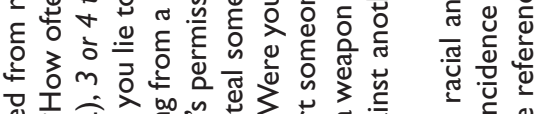

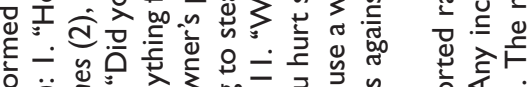

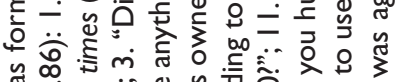

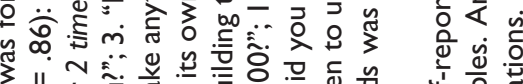

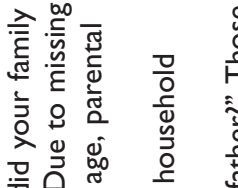

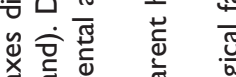

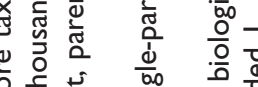

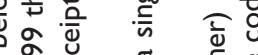

हो

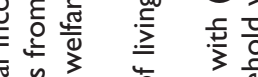

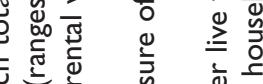

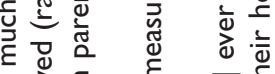

उ桴

3

过

들

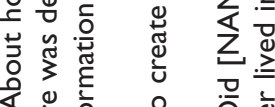

产龸

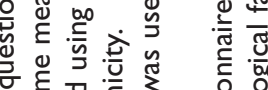

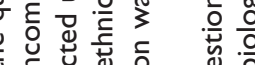

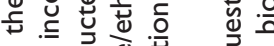

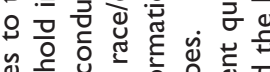

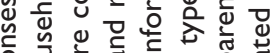

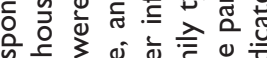

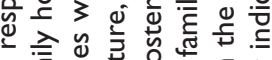

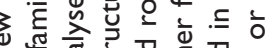

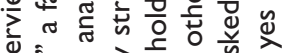

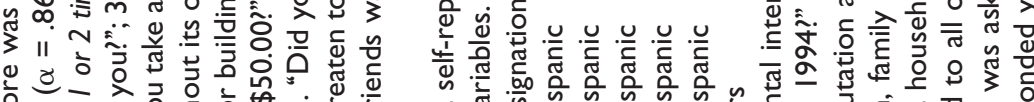

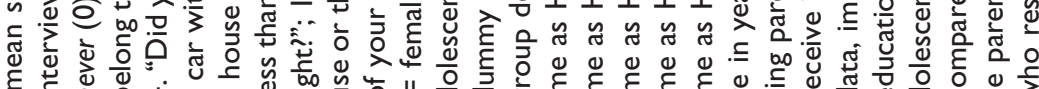
这.
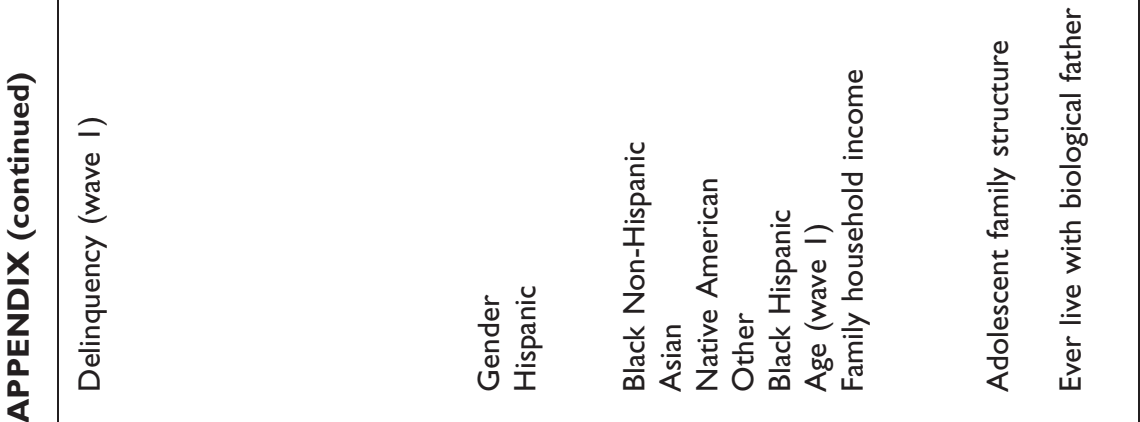


\section{ACKNOWLEDGMENTS}

This research uses data from Add Health, a program project directed by Kathleen Mullan Harris and designed by J. Richard Udry, Peter S. Bearman, and Kathleen Mullan Harris at the University of North Carolina at Chapel Hill and funded by grant P01-HD31921 from the Eunice Kennedy Shriver National Institute of Child Health and Human Development, with cooperative funding from 23 other federal agencies and foundations. Special acknowledgment is due Ronald R. Rindfuss and Barbara Entwisle for assistance in the original design. Information on how to obtain the Add Health data files is available on the Add Health Web site (http://www.cpc.unc.edu/addhealth). No direct support was received from grant P01-HD31921 for this analysis.

\section{FUNDING}

The author(s) disclosed receipt of the following financial support for the research, authorship, and/or publication of this article: We appreciate the support of a grant from the Law and Social Sciences Program of the National Science Foundation (No. SES 0617275) for this work.

\section{REFERENCES}

Anderson, Elijah. 1990. Streetwise: Race, Class and Change in an Urban Community. Chicago: University of Chicago Press.

Arum, Richard and Irene R. Beattie. 1999. "High School Experiences and the Risk of Adult Incarceration." Criminology 37:515-37.

Arum, Richard and Gary LaFree. 2008. "Educational Attainment, Teacher/Student Ratios and Adult Incarceration Risk among U.S. Birth Cohorts since 1910." Sociology of Education 81:397-421.

Blumstein, Alfred. 2007. "The Roots of Punitiveness in a Democracy." Journal of Scandanavian Studies in Criminology and Crime Prevention 8:S1:2-16.

Casas-Gil, Maria J. and Jose L. Navarro-Guzman. 2002. "School Characteristics among Children of Alcoholic Parents." Psychological Reports 90: 341-48.

Cho, Rosa Minhyo. 2009. “The Impact of Maternal Imprisonment on Children's Educational Achievement: Results from Children in Chicago Public Schools." The Journal of Human Resources 44:772-97.

Cho, Rosa Minhyo. 2010. "Maternal Incarceration and Children's Adolescent Outcomes: Timing Versus Dosage." Social Service Review 84:257-82.

Cho, Rosa. 2011. "Understanding the Mechanism behind Maternal Imprisonment and Adolescent School Dropout." Family Relations, 60(3): 272-289.
Clear, Todd R. 2007. Imprisoning Communities: How Mass Incarceration Makes Disadvantaged Neighborhoods Worse. New York: Oxford University Press.

Christle, Christina, Krinstine Jolivette, and Michael Nelson. 2005. "Breaking the School to Prison Pipeline: Identifying School Risk and Protective Factors for Youth Delinquency." Exceptionality 13:69-88.

Cohen, Jonathan, Elizabeth McCabe, Nicholas Michelli, and Terry Pickeral. 2009. "School Climate: Research, Policy, Practice, and Teacher Education." Teachers College Record 111:180-213.

Comfort, Megan. 2008. Doing Time Together: Love and Family in Shadow of the Prison. Chicago: University of Chicago Press.

Condron, Dennis. 2009. "Social Class, School and Non-school Environments, and Black/White Inequalities in Children's Learning." American Sociological Review 74:685-708.

Crosnoe, Robert and Catherine Riegle-Crumb. 2007. "A Life Course Model of Education and Alcohol Use." Journal of Health and Social Behavior 48:267-82.

Dallaire, Danielle, Ann Ciccone, and Laura Wilson. 2010. "Teachers' Experiences with and Expectations of Children with Incarcerated Parents." Journal of Applied Developmental Psychology 31:281-90.

Elder, Glen. 1994. "Time, Human Agency, and Social Change." Social Psychology Quarterly 57:4-15.

Fenning, Pamela and Jennifer Rose. 2007. "Over-representation of African American Students in Exclusionary Discipline: The Role of School Policy." Urban Education 42:536-59.

Fishbein, Diana. 1990. "Biological Perspectives in Criminology." Criminology 28:27-72.

Foster, Holly and John Hagan. 2007. "Incarceration and Intergenerational Social Exclusion.” Social Problems 54:399-433.

Foster, Holly and John Hagan. 2009. "The Mass Incarceration of American Parents: Issues of Race/ Ethnicity, Collateral Consequences, and Prisoner Re-entry." Annals of the American Academy of Political and Social Science 623:195-213.

Friedman, Sidney and T. Conway Esselstyn. 1965. "The Adjustment of Children of Jail Inmates." Federal Probation 4:55-9.

Garland, David. 2001a. The Culture of Control: Crime and Social Order in Contemporary Society. Chicago: University of Chicago Press.

Garland, David. 2001b. "Introduction: The Meaning of Mass Imprisonment." Pp. 1-3 in Mass Imprisonment: Social Causes and Consequences, edited by D. Garland. Thousand Oaks, CA: SAGE.

Glaze, Lauren E. and Laura M. Maruschak. 2008. Parents in Prison and Their Minor Children. Washington, DC: U.S. Department of Justice.

Gottfredson, Denise. 2001. Schools and Delinquency. New York: Cambridge University Press. 
Gottfredson, Michael and Travis Hirschi. 1990. A General Theory of Crime. Palo Alto, CA: Stanford University Press.

Hagan, John and Ronit Dinovitzer. 1999. "Collateral Consequences of Imprisonment for Children, Communities, and Prisoners." Crime \& Justice 26: 121-62.

Hagan, John and Bill McCarthy. 1998. Mean Streets: Youth Crime and Homelessness. New York: Cambridge University Press.

Harris, Kathleen Mullan. 2009. The National Longitudinal Study of Adolescent Health (Add Health), Waves I \& II, 1994-1996; Wave III, 2001-2002; Wave IV, 2007-2009 [MRDF]. Chapel Hill, NC: Carolina Population Center, University of North Carolina at Chapel Hill.

Harris, K. M., C. T. Halpern, E. Whitsel, J. Hussey, J. Tabor, P. Entzel, and J. R. Udry. 2009. The National Longitudinal Study of Adolescent Health: Research Design. Retrieved April 12, 2010 (http:// www.cpc.unc.edu/projects/addhealth/design)

Hirschfield, Paul J. 2008. "Preparing for Prison? The Criminalization of School Discipline in the USA." Theoretical Criminology, 12:79-101.

Jencks, Christopher. 1972. Inequality: A Reassessment of Family and Schooling in America. New York: Basic Books.

Kearney, Christopher A. 2008. "School Absenteeism and School Refusal Behavior in Youth: A Contemporary Review." Clinical Psychology Review 28:451-71.

Kupchicka, Aaron and Torin Monahan. 2006. "The New American School: Preparation for Post-industrial Discipline." British Journal of Sociology of Education 27:617-31.

Leventhal, Tama and Jeanne Brooks-Gunn. 2000. "The Neighborhoods They Live in: The Effects of Neighborhood Residence on Child and Adolescent Outcomes." Psychological Bulletin 126:309-37.

Lynch, James P. and William J. Sabol. 2004. "Effects of Incarceration on Informal Social Control in Communities." Pp. 135-64 in Imprisoning America: The Social Effects of Mass Incarceration, edited by M. Patillo, D. Weiman, and B. Western. New York: Russell Sage Foundation.

Mauer, Marc. 2009. The Changing Racial Dynamics of the War on Drugs. Washington, DC: The Sentencing Project.

McLanahan, Sara and Gary Sandefur. 1994. Growing Up with a Single Parent: What Hurts, What Helps? Cambridge, MA: Harvard University Press.

Muller, Chandra, Jennifer Pearson, Catherine Riegle-Crumb, Jennifer Harris Requejo, Kenneth A. Frank, Kathryn S. Schiller, R. Kelly Raley, Amy G. Langenkamp, Sarah Crissey, Anna Strassmann Mueller, Rebecca Callahan, Lindsey Wilkinson, and Samuel Field. 2007. Wave III Education Data: Design and Implementation of the Adolescent
Health and Academic Achievement Study. Chapel Hill, NC: Carolina Population Center, UNC-CH.

Mumola, C. J. 2000. Incarcerated parents and their children. Washington, DC: US Department of Justice, Office of Justice Programs.

Murray, Joseph and David P. Farrington. 2008. "The Effects of Parental Imprisonment on Children." Crime \& Justice 37:133-206.

Oliver, Pamela. 2008. Racial Patterns in State Trends in Prison Admissions 1983-2003: Drug and Non-drug Sentences and Revocations: Introduction and National Graphs. Retrieved November 26, 2011 (http://www.ssc.wisc.edu/ oliver/RACIAL/StateTre nds/RacialPatternsNCRPintroduction.pdf).

Pager, Devah. 2003. "The Mark of a Criminal Record." American Journal of Sociology 108:937-75.

Pager, Devah. 2007. Marked: Race, Crime, and Finding Work in an Era of Mass Incarceration. Chicago: University of Chicago Press.

Pettit, Becky and Bruce Western. 2004. "Mass Imprisonment and the Life Course." American Sociological Review 69:151-69.

Raudenbush, Steven W. 1988. "Educational Applications of Hierarchical Linear Models: A Review.” Journal of Educational Statistics 13:85-116.

Raudenbush, Stephen W. and Anthony S. Bryk. 2002. Hierarchical Linear Models: Applications and Data Analysis Methods. 2nd ed. Thousand Oaks, CA: SAGE

Raudenbush, Stephen W., Anthony Bryk, Yuk Fai Cheong, and Mathilda du Toit. 2004. HLM 6 Hierarchical Linear and Nonlinear Modeling. Lincolnwood, IL: Scientific Software International.

Resnick, M. D., P. Bearman, R. W. Blum, K. E. Bauman, K. M. Harris, J. Jones, J. Tabor, T. Beuhring, R. Seivne, M. Shew, M. Ireland, L. Beringer, and J. R. Udry. 1997. "Protecting Adolescents from Harm: Findings from the National Longitudinal Study of Adolescent Health." Journal of the American Medical Association 278:823-32.

Riegle-Crumb, Catherine, Chandra Muller, Kenneth Frank, and Kathryn S. Schiller. 2005. National Longitudinal Study of Adolescent Health: Wave III, education data. Chapel Hill: Carolina Population Center, University of North Carolina at Chapel Hill.

Rose, Dina and Todd Clear. 1998. "Incarceration, Social Capital, and Crime: Implications for Social Disorganization Theory." Criminology 36:441-80.

Sabol, William and James Lynch. 2003. "Assessing the Longer-run Consequences of Incarceration: Effects on Families and Employment." Pp. 3-26 in Crime Control and Social Justice: The Delicate Balance, edited by D. Hawkins, S. Myers, and R. Stone. Westport, CT: Greenwood Press.

Sampson, Robert and John Laub. 1995. Crime in the Making: Pathways and Turning Points through Life. Cambridge, MA: Harvard University Press. 
Sampson, Robert and Charles Loeffler. 2010. "Punishment's Place: The Local Concentration of Mass Incarceration." Daedalus 139(3):20-31.

Sampson, Robert and William Julius Wilson. 1995. "Toward a Theory of Race, Crime, and Urban Inequality." Pp. 37-56 in Crime and Inequality, edited by J. Hagan and R. Peterson. Stanford, CA: Stanford University Press.

Sander, Janay. 2010. "School Psychology, Juvenile Justice, and the School to Prison Pipeline." Communique 39:4-5.

Sharkey, Patrick. 2008. "The Intergenerational Transmission of Context." American Journal of Sociology 113:931-69.

Sharkey, Patrick. 2010. "The Acute Effect of Local Homicides on Children's Cognitive Performance." Proceedings of the National Academy of Sciences 107:11733-1738.

Simon, Jonathan. 2007. "Rise of the Carceral State." Social Research 74:471-508.

Solomon, R. Patrick. 2004. "Schooling in Babylon, Babylon in School: When Racial Profiling and Zero Tolerance Converge." Canadian Journal of Educational Administration and Policy 33.

Stanton, Ann M. 1980. When Mothers Go to Jail. Lexington, MA: Lexington Books.

Trice, Ashton D. and JoAnne Brewster. 2004. "The Effects of Maternal Incarceration on Adolescent Children." Journal of Police and Criminal Psychology 19:27-35.

Tuzzolo, Ellen and Damon Hewitt. 2006/7. "Rebuilding Inequity: The Re-emergence of the School-to-prison Pipeline in New Orleans." High School Journal 90: 59-68.

Udry, J. Richard and Peter S. Bearman. 1998. "New Methods for New Research on Adolescent Sexual Behavior." Pp. 241-69 in New Perspectives on Adolescent Risk Behavior, edited by R. Jessor. Cambridge, UK: Cambridge University Press.

Vacha, Edward F. and T. F. McLaughlin. 1992. "The Social Structural, Family, School, and Personal Characteristics of At-risk Students: Policy Recommendations for School Personnel." Journal of Education 174:9-25.
Wakefield, Sara and Christopher Uggen. 2010. "Incarceration and Stratification." Annual Review of Sociology 36:387-406.

Wakefield, Sara and Christopher Wildeman. 2011. "Mass Imprisonment and Racial Disparities in Childhood Behavioral Problems." Criminology \& Public Policy 10:793-817.

Western, Bruce. 2006. Punishment and Inequality in America. New York: Russell Sage Foundation.

Western, Bruce, Leonard M. Lopoo, and Sara McLanahan. 2004. "Incarceration and Bonds between Parents in Fragile Families." Pp. 21-45 in Imprisoning American: The Social Effects of Mass Incarceration, edited by Mary Pattillo, David Weiman, and Bruce Western. New York: Russell Sage Foundation.

Wildeman, Christopher. 2009. "Parental Incarceration, the Prison Boom, and the Concentration of Childhood Disadvantage." Demography 46:265-80.

Wilson, James Q. and Richard Herrnstein. 1985. Crime and Human Nature. New York: Simon and Schuster.

Wilson, William Julius. 1996. When Work Disappears: The World of the New Urban Poor. New York: Knopf.

\section{$\mathrm{BIOS}$}

John Hagan is John D. MacArthur professor of Sociology and Law at Northwestern University and Co-Director of the Center on Law \& Globalization at the American Bar Foundation in Chicago. He received the Stockholm Prize in Criminology in 2009. His most recent book is Who Are the Criminals? Crime Policy from the Age of Roosevelt to the Age of Reagan (Princeton University Press 2010).

Holly Foster, $\mathrm{PhD}$ is an associate professor in the Department of Sociology at Texas A\&M University. Her interests include life course sociology, social inequality, and crime and deviance. Her research includes work on parental incarceration effects on children's educational outcomes and social exclusion, exposure to violence and children's well-being, and delinquency and depression in the transition to adulthood. 